\title{
Plasmodium infection reduces the volume of the viral reservoir in SIV-infected rhesus macaques receiving antiretroviral therapy
}

\author{
Xiao-Yong Zhan ${ }^{\dagger}$, Nina Wang ${ }^{\dagger}$, Guangjie Liu, Limei Qin, Wanwan Xu, Siting Zhao, Li Qin ${ }^{*}$ and Xiaoping Chen ${ }^{*}$
}

\begin{abstract}
Background: Previous studies indicated that Plasmodium infection activates the immune system, including memory CD4+ T cells, which constitute the reservoir of human immunodeficiency virus type-1 (HIV-1). Therefore, we postulated that co-infection with malaria might activate the reservoir of HIV-1. To test this hypothesis, we used a rhesus macaque model of co-infection with malaria and simian immunodeficiency virus (SIV), along with antiretroviral therapy (ART).

Results: Our results showed that Plasmodium infection reduced both the replication-competent virus pool in resting CD4+ T cells and the integrated virus DNA (iDNA) load in peripheral blood mononuclear cells in the monkeys. This reduction might be attributable to malaria-mediated activation and apoptotic induction of memory CD4+ T cells. Further studies indicated that histone acetylation and NF-kappaB (NF-kB) activation in resting CD4+ T cells may also play an important role in this reduction.

Conclusions: The findings of this work expand our knowledge of the interaction between these two diseases. As more HIV-1-infected individuals in malaria-endemic areas receive ART, we should explore whether any of the patients co-infected with Plasmodium experience virologic benefits.
\end{abstract}

Keywords: HIV-1, SIV, AIDS, Plasmodium, Malaria, Rhesus macaque model, Co-infection, ART, Viral reservoir

\section{Background}

Human immunodeficiency virus type-1 (HIV-1) infection is one of the most important global health problems [1]. The virus replicates within and destroys $\mathrm{CD} 4+\mathrm{T}$ cells in patients, ultimately leading to acquired immune deficiency syndrome (AIDS). Antiretroviral therapy (ART) can dramatically control the replication of HIV-1 and decrease viral loads in HIV-1-infected individuals. Many HIV-1positive individuals have recently begun receiving ART in low- and middle-income regions. The pool of resting CD4+ $\mathrm{T}$ cells, including $\mathrm{CD} 4+$ central memory $\mathrm{T}\left(\mathrm{T}_{\mathrm{CM}}\right)$ and effector memory $\mathrm{T}\left(\mathrm{T}_{\mathrm{EM}}\right)$ cells, is a major reservoir because ART does not affect the provirus within these cells $[2,3]$. These cells thus provide a long-lasting cellular reservoir for

\footnotetext{
* Correspondence: qin_li@gibh.ac.cn; chen_xiaoping@gibh.ac.cn

${ }^{\dagger}$ Equal contributors

Laboratory of Pathogen Biology, State Key Laboratory of Respiratory Disease, Center for Infection and Immunity, Guangzhou Institutes of Biomedicine and Health, Chinese Academy of Sciences, No. 190 Kaiyuan Avenue, Luogang District, Guangzhou Science Park, Guangzhou 510530, Guangdong Province, China
}

\section{() Biomed Central

HIV-1 [2,3]. As a result, one of the major therapeutic strategies for eradication of the HIV-1 reservoir is to reactivate the latent provirus in resting CD4+ T cells [4]. This strategy is promising for purging HIV-1 from this reservoir.

Malaria is another important infectious disease, and it has been shown to strongly activate the immune system [5]. In particular, Plasmodium antigens can activate T cells via antigen-presenting cells (APCs) [5], and polyclonal activated $\mathrm{T}$ and $\mathrm{B}$ cells, including memory $\mathrm{CD} 4+\mathrm{T}$ cells, are observed during the blood stage of Plasmodium infection in mice and monkeys [6-8].

Previous studies have suggested that malaria has effects on HIV-1 infection [9-12]. Specifically, malaria infection might strongly activate CD4+ T cells; up-regulate proinflammatory cytokines, such as interleukin-6 (IL-6) and tumor necrosis factor-alpha (TNF- $\alpha$ ); and induce activation of the virus $[9,13,14]$. However, ART may control HIV-1 replication in CD4+ T cells, even during malaria infection. We therefore hypothesized that the impact of malaria on HIV-1 infection under ART might be different from the impact in those situations without ART. More 
specifically, we hypothesized that malaria infection might activate latently infected resting CD4+ T cells and induce latent virus reactivation, thus reducing the volume of the viral reservoir under ART.

To test our hypothesis, we utilized a rhesus macaque model of co-infection with Plasmodium cynomolgi (Pc, a nonlethal monkey malaria Plasmodium species) and simian immunodeficiency virus (SIVmac251, SIV) under ART. As expected, malaria activated the CD4+ T cells, decreased the integrated virus DNA (iDNA) load in peripheral blood mononuclear cells (PBMCs) and reduced the replicationcompetent virus pool in resting CD4+ T cells. We also found increased levels of apoptotic memory CD4+ T cells during the course of Pc infection. Additionally, malaria induced histone acetylation and activation of NF-kappaB $(\mathrm{NF}-\mathrm{kB})$ in resting CD4+ T cells. All of these factors might contribute to the reduction of the viral reservoir.

\section{Results}

\section{Pc infection reduced the size of the viral reservoir in} SIV-infected macaques

The design of the animal experiments is shown in Figure 1. Twelve Chinese-origin rhesus macaques (Macaca mulatta) were inoculated intravenously with $10,00050 \%$ tissue culture infectious doses of SIVmac251 and were randomly divided into two groups ( $\mathrm{n}=6$ per group): the ART group (ART only) and the ART + Pc group (ART plus Pc infection). SIV infection resulted in certain typical virological and immunological changes in the monkeys that were similar to those reported previously (Additional file 1: Figure S1) [15]. The animals in the ART + Pc group displayed typical clinical manifestations of malaria during PC infection (data not shown).

Pc infection significantly decreased the frequency of resting CD4+ $\mathrm{T}$ cells harboring replication-competent virus (defined as infectious units per million cells, or IUPM) (Figure 2A and B, Table 1). After the malaria was treated, the IUPM in the ART + Pc group remained significantly lower at weeks 68 and 73 compared with the IUPM in the ART group before ART was terminated ("No-malaria phase," as shown in Figure 1; $P=0.001$; Figure $2 \mathrm{~B}$ ). The ART + Pc group also showed a lower iDNA load in PBMCs after Pc infection (under ART) compared with the load in the ART group (means of 0.23 and 1.11 copies per $10^{5}$ PBMCs, respectively; $P=0.047$; Figure $2 \mathrm{C}$ ). These results suggested that under ART, Pc infection decreased the viral reservoirs in SIV-infected macaques.

\section{Pc infection increased the apoptosis of memory CD4+ T cells}

Induction of memory-cell apoptosis potentially leads to reduction of SIV reservoirs in rhesus macaques [16]. To determine whether Pc infection affects CD4+ $\mathrm{T}_{\mathrm{CM}}$ and $\mathrm{T}_{\mathrm{EM}}$ cell viability, we measured the percentages of $C D 4+T_{C M}$ and $\mathrm{T}_{\mathrm{EM}}$ cells with annexin $\mathrm{V}$ expressed on the cell membrane. The marker Ki67 was also used to evaluate the proliferation of these cells. CD28 + CD95 + CD4+ T cells were defined as CD4+ $\mathrm{T}_{\mathrm{CM}}$ cells, CD28 + CD95-CD4+ T cells were defined as CD4 $+\mathrm{T}_{\mathrm{EM}}$ cells in rhesus macaques according to previously report [17]. Our results suggested that Pc infection did not increase the proliferation levels of CD4 $+\mathrm{T}_{\mathrm{CM}}$ and $\mathrm{T}_{\mathrm{EM}}$ cells (data not shown). However, the apoptosis levels of CD4+ $\mathrm{T}_{\mathrm{CM}}$ cells in the ART + Pc group were higher than those in the ART group during the malaria phase (especially during the acute phase, from weeks $49-53$; means of $8.25 \%$ and $6.56 \%$, respectively; $P=0.12$; Figure $3 \mathrm{~A})$. There were also significantly more apoptotic CD4+ $\mathrm{T}_{\mathrm{EM}}$ cells in the ART + Pc group than in the ART group (means of $12.09 \%$ and $7.46 \%$, respectively; $P=0.046$; Figure $3 \mathrm{~B})$. We also observed that the number of iDNA copies in PBMCs during the malaria phase was negatively correlated with the apoptosis levels of CD4+ $\mathrm{T}_{\mathrm{CM}}$ cells in the two groups $(P=0.025, r=-0.372$; Figure $3 C)$. Additionally, the number of iDNA copies was negatively

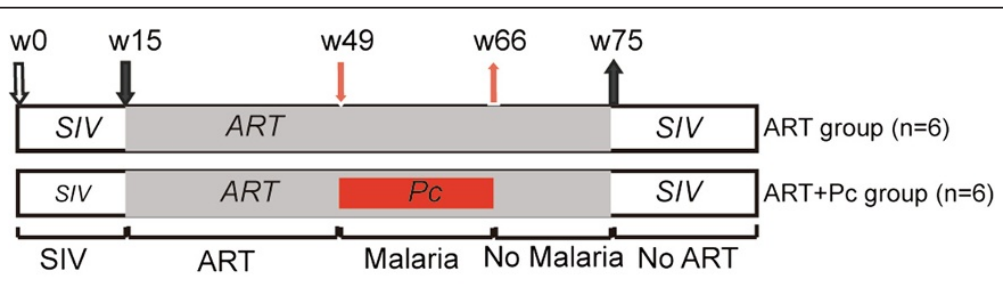

$\Downarrow$ week 0: Inoculation with SIV (All monkeys)

week 15: Start of ART (All monkeys)

I week 49: Inoculation of $P$. cynomolgi (Pc) (ART+Pc group)

week 66: Termination of $P c$ infection (ART+Pc group)

week 75: Termination of ART (All monkeys)

Figure 1 Animal study design. At week 0, 12 monkeys in the 2 groups were infected with SIV. At week 15, all monkeys started to receive ART (downward black arrow). During weeks 49-66, 6 monkeys in the ART + Pc group were co-infected with Pc (red arrows and box). At week 75, ART was terminated in all monkeys (upward black arrow). The light gray boxes indicate ART, and the light red box indicates PC infection. 


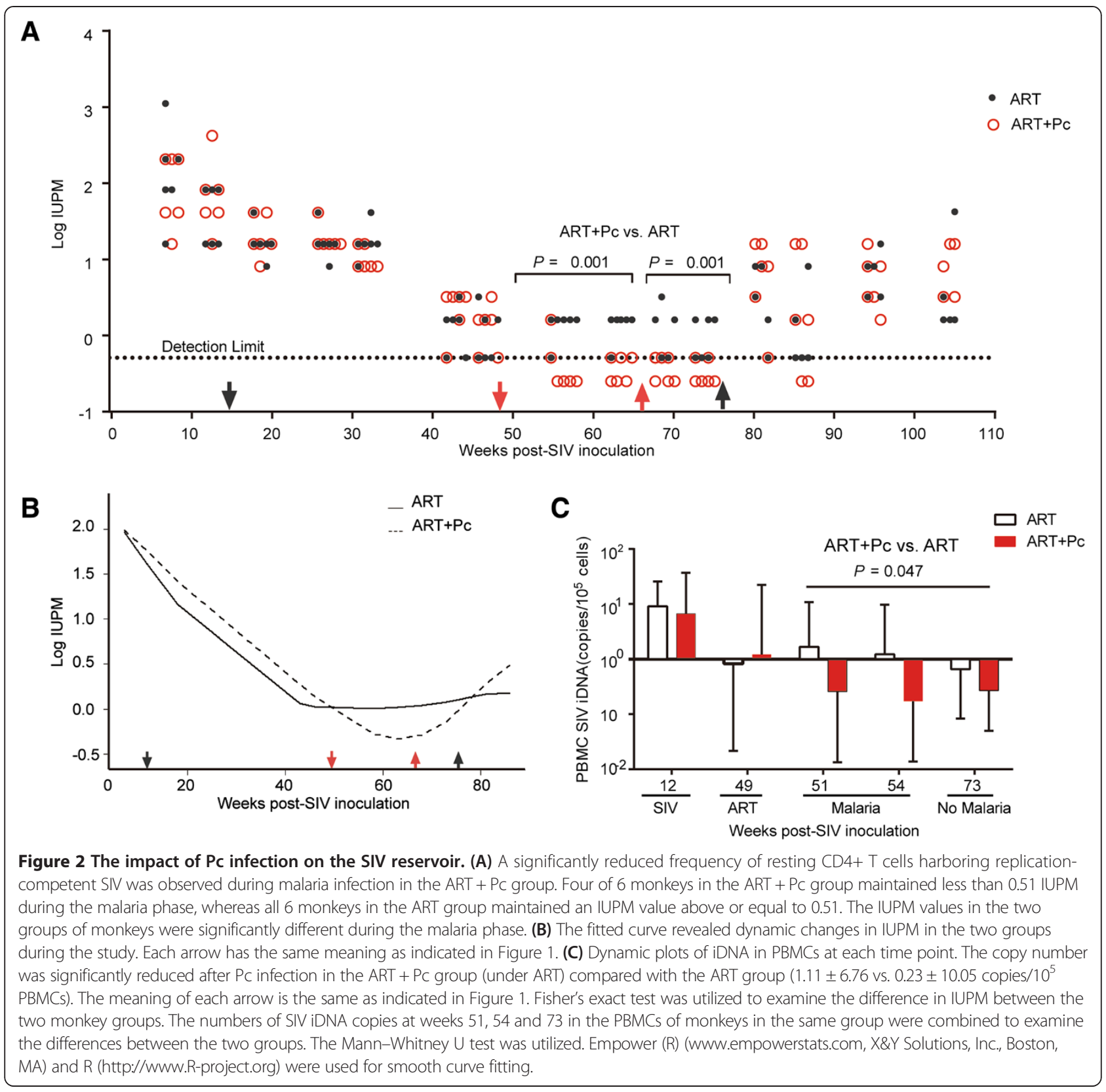

correlated with the apoptosis levels of CD4+ $\mathrm{T}_{\mathrm{EM}}$ cells $(P=0.11, r=-0.270$, respectively; Figure $3 \mathrm{D})$. These results suggested that the reduction of the viral reservoir in the ART + Pc group might have been associated with the increased levels of CD4+ $\mathrm{T}_{\mathrm{CM}}$ and $\mathrm{T}_{\mathrm{EM}}$ cell apoptosis during the course of malaria.

Pc infection selectively activated the immune system in SIV-positive monkeys under ART, which potentially led to memory CD4+ T cell apoptosis and a reduction of the SIV reservoir

Our previous study using the rhesus monkey model indicated that $\mathrm{Pc}$ infection activated CD4+ $\mathrm{T}$ cells in
SIV-negative animals [7]. In the present study, we examined activation markers of CD4+ T cells in SIV-positive animals under ART, including HLA-DR and CD38 co-expression on CD4+ $\mathrm{T}$ cells and plasma cytokine concentrations. Malaria did not increase the concentrations of plasma cytokines such as TNF- $\alpha$, interleukin-7 (IL-7), interleukin-2 (IL-2, represented by its activity marker, the IL-2 receptor, or IL-2R) and IL-6, which have been shown to promote provirus reactivation [18-21] and to represent activation of the immune system (Additional file 2: Figure S2A). However, CD4+ T cell activation was found in the ART $+\mathrm{Pc}$ group because a greater percentage of HLA-DR + CD38 + $\mathrm{CD} 4+\mathrm{T}$ cells, which is a robust measure of CD4+ $\mathrm{T}$ cell 
Table 1 Resting CD4+ T cells' IUPM for each monkey

\begin{tabular}{|c|c|c|c|c|c|c|c|}
\hline \multirow{3}{*}{\multicolumn{2}{|c|}{$\begin{array}{l}\text { Monkey grouping } \\
\text { and ID }\end{array}$}} & \multicolumn{6}{|c|}{ Phase, week post-SIV inoculation, and IUPM } \\
\hline & & \multicolumn{2}{|c|}{ ART phase } & \multicolumn{2}{|c|}{ Malaria phase } & \multicolumn{2}{|c|}{ No-malaria phase } \\
\hline & & Week 43 & Week 46 & Week 58 & Week 63 & Week 68 & Week 73 \\
\hline \multirow[t]{6}{*}{ ART } & 26 & 1.6 & 0.51 & 1.6 & 1.6 & 1.6 & 0.51 \\
\hline & 28 & 0.51 & 0.51 & 1.6 & 1.6 & 0.51 & 1.6 \\
\hline & 30 & 0.51 & 0.51 & 1.6 & 1.6 & 1.6 & 0.51 \\
\hline & 32 & 3.2 & 3.2 & 1.6 & 1.6 & 0.51 & 1.6 \\
\hline & 34 & 1.6 & 1.6 & 1.6 & 1.6 & * & 0.51 \\
\hline & 36 & 1.6 & 1.6 & 0.51 & 0.51 & 3.2 & 1.6 \\
\hline \multirow[t]{6}{*}{$A R T+P C$} & 27 & 3.2 & 1.6 & 0.51 & 0.51 & * & $<0.51$ \\
\hline & 29 & 0.51 & 0.51 & $<0.51$ & $<0.51$ & 0.51 & 0.51 \\
\hline & 31 & 1.6 & 1.6 & $<0.51$ & $<0.51$ & 0.51 & $<0.51$ \\
\hline & 33 & 3.2 & 3.2 & 1.6 & 0.51 & $<0.51$ & $<0.51$ \\
\hline & 35 & 1.6 & 1.6 & $<0.51$ & $<0.51$ & $<0.51$ & 0.51 \\
\hline & 37 & 3.2 & 0.51 & $<0.51$ & $<0.51$ & 0.51 & $<0.51$ \\
\hline
\end{tabular}

*Sorted resting CD4+ T cells were insufficient for co-culture assays; therefore, no data were obtained. The detection limit was 0.51 , and IUPM values less than the detection limit are indicated as " $<0.51$ " or defined as the most likely largest value $(0.32)$ to formulate the fitted curve in Figure $2 \mathrm{~B}$.

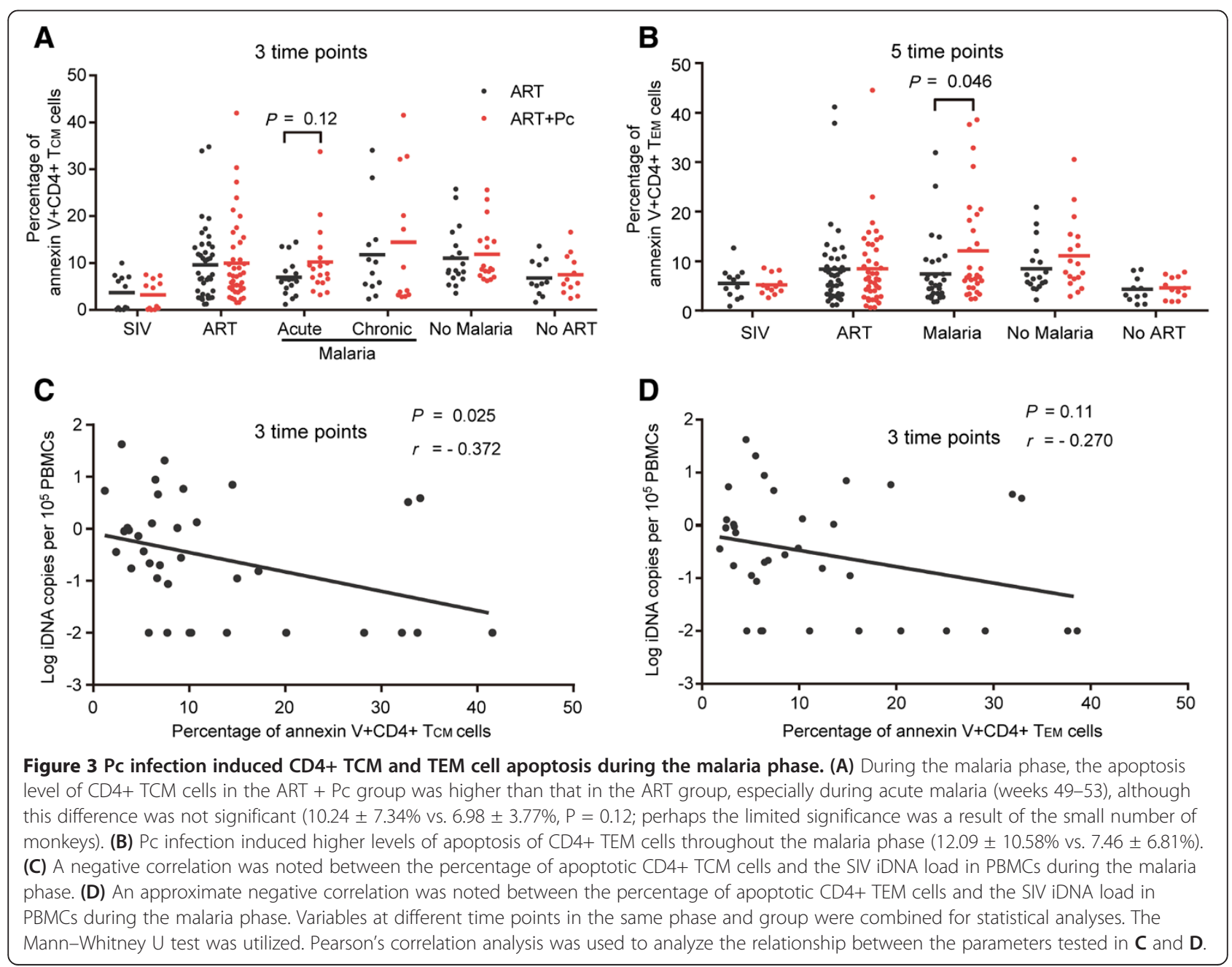


activation, was observed (Figure 4A). Higher concentrations of plasma neopterin (an activity marker of interferon-gamma, or IFN- $\gamma$ ) were also observed in the $\mathrm{ART}+\mathrm{Pc}$ group during malaria infection (Additional file 2: Figure S2B). There was a significant positive correlation between plasma neopterin levels and the percentage of HLA-DR + CD38 + CD4+ T cells during the malaria phase $(P=0.002 ; r=0.493$; Additional file 2 : Figure $S 2 C)$, suggesting that the activation of CD4 $+\mathrm{T}$ cells was associated with higher concentrations of neopterin induced by malaria. Moreover, the CD4+ T cell activation level, as indicated by the percentage of HLA-DR + CD $38+C D 4+T$ cells, was shown to be positively correlated with the percentage of annexin $\mathrm{V}+\mathrm{CD} 4+\mathrm{T}_{\mathrm{CM}}$ and $\mathrm{T}_{\mathrm{EM}}$ cells during the malaria phase $(P=0.031, r=0.44$ and $P=0.050$, $r=0.404$; respectively; Figure $4 \mathrm{~B}$ and $\mathrm{C}$ ). The CD4+ T cell activation level during the malaria phase was also negatively correlated with the iDNA levels in PBMCs $(P=0.005, r=-0.458$; Figure 4D). Additionally, a greater percentage of CCR $5+$ CD4 $+\mathrm{T}$ cells, which have also been linked to the activation of CD4+ T cells and the immune system [22,23], was observed in the ART + Pc group during malaria infection (Additional file 2: Figure S2D). These results suggested that malaria activated CD4+ T cells, which might have led to the apoptosis of certain CD4+ $\mathrm{T}_{\mathrm{CM}}$ and $\mathrm{T}_{\mathrm{EM}}$ cells and contributed to the reduction of the SIV reservoir.

\section{Pc infection induced histone acetylation in latently SIV-infected resting CD4+ T cells and reactivated the provirus in these cells}

Previous studies showed that histone acetylation in resting $\mathrm{CD} 4+\mathrm{T}$ cells could induce reservoir purging $[24,25]$. We thus examined the histone acetylation levels in peripheral blood lymphocytes (PBLs) in the monkeys during different phases. The results showed that the levels of global histone acetylation in PBLs, as measured based on mean fluorescence intensity (MFI), were much higher in the ART + Pc group during Pc infection than

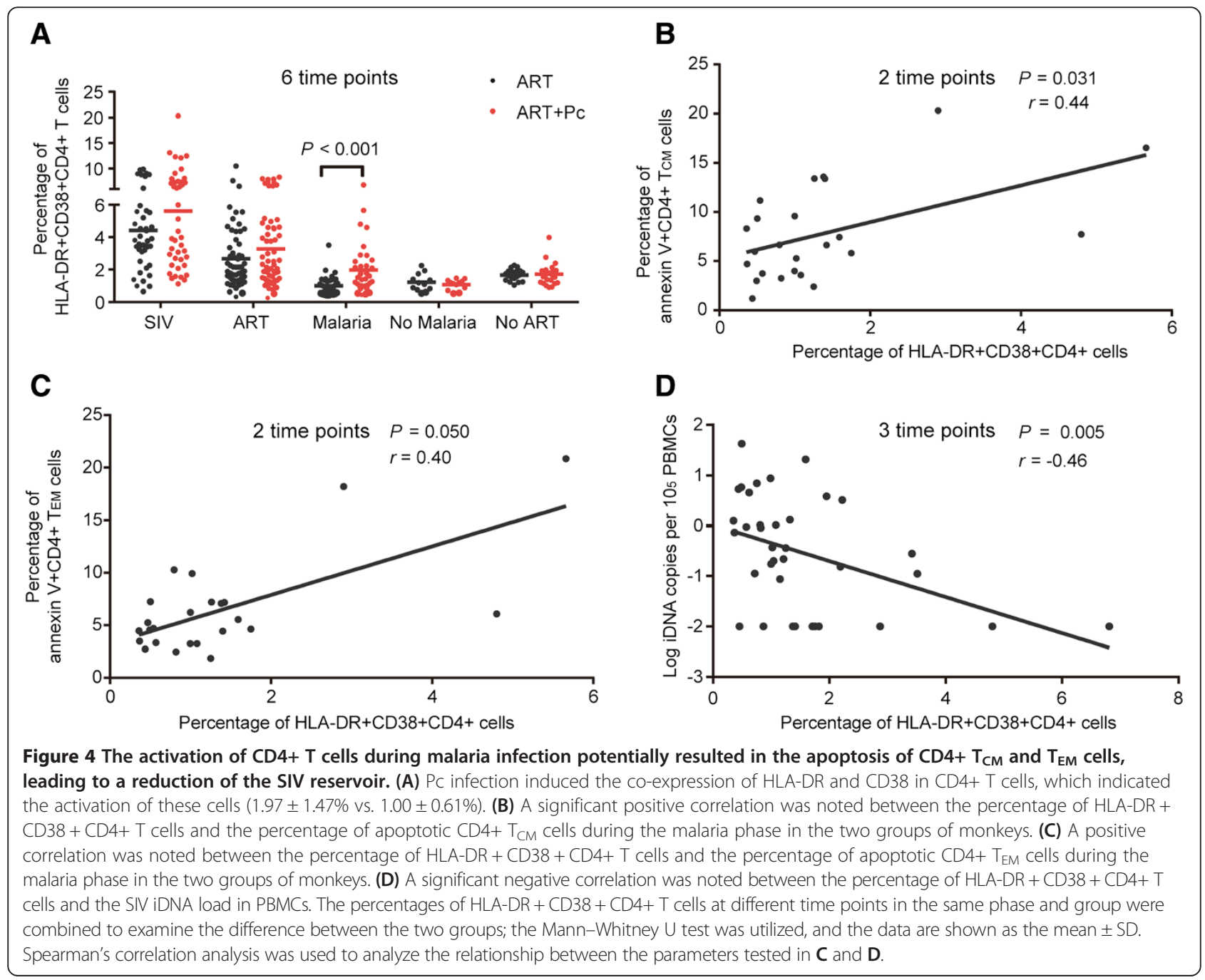


the levels in the ART group (MFI of 188.90 vs. 125.96; $P=0.001$; Figure $5 \mathrm{~A}-\mathrm{C}$ ).

We further explored whether the products of malaria parasites participated in the purging of the viral reservoir. A chloroquine-sensitive strain (3d7) and a chloroquineresistant strain (dd2) of the human malaria parasite Plasmodium falciparum (Pf) were used for these tests. In particular, we prepared the Pf $3 \mathrm{~d} 7$ metabolite hemozoin (HZ) and soluble extracts to test their potencies in reactivating latent cells. An in vitro assay was then performed with J-Lat 10.6 cells to determine whether Pf HZ or soluble extract could reactivate these latently infected CD4+ $\mathrm{T}$ cells by observing the expression of HIV-1-pseudotyped virus. The results showed that $5 \mu \mathrm{g} / \mathrm{ml}$ Pf soluble extract could reactivate the J-Lat 10.6 cells. Increased GFP expression after 24-48 hours of co-incubation was observed, indicating the expression of latent virus. However, 10$100 \mu \mathrm{g} / \mathrm{ml} \mathrm{HZ}$ did not activate the J-Lat 10.6 cells (Figure 6A). Additionally, valproic acid (VPA) and phytohemagglutinin (PHA) were used as positive controls. Both compounds induced the expression of latent virus in J-Lat 10.6 cells, but only VPA induced more acetylated histones (Figure 6B). Fluorescence-activated cell sorting (FACS) assays also showed that $5 \mu \mathrm{g} / \mathrm{ml}$ Pf soluble extract could induce more histone acetylation in J-Lat 10.6 cells after 24- or 48-hour co-incubation. In resting CD4+ T cells isolated from the PBMCs of the SIV-infected monkeys, $50 \mu \mathrm{g} / \mathrm{ml} \mathrm{Pf}$ soluble extract could also induce histone acetylation after a 24- or 48-hour co-incubation (Figure 6C). In contrast, $1 \mu \mathrm{g} / \mathrm{ml}$ Pf soluble extract did not induce much more histone acetylation in J-Lat 10.6 cells (Additional file 3: Figure S3), and $25 \mu \mathrm{g} / \mathrm{ml}$ Pf soluble extract dramatically induced the death of J-Lat 10.6 cells (data not shown).
Unlike the situation in J-Lat cells, $50 \mu \mathrm{g} / \mathrm{ml}$ Pf soluble extract could sufficiently induce significantly more histone acetylation in the monkey resting CD4+ T cells (Additional file 3: Figure S3). These results indicated that the sensitivity of the J-Lat cell line and primary monkey cells to Pf extract was not the same.

Chromatin immunoprecipitation (ChIP) assays showed that the amounts of acetylated histone $\mathrm{H} 3$ (AcH3) bound to the core promoter region within the HIV1 and SIV long terminal repeats (LTRs) increased when cells were co-incubated with Pf soluble extract Figure 6D and E). In particular, in J-Lat 10.6 cells, the acetylated histone levels increased 1.65-fold when the cells were stimulated with Pf $3 \mathrm{~d} 7$ extract and increased 3.07-fold when the cells were stimulated with Pf dd2 extract. In contrast, in monkey PBMCs, the levels increased 3.10-fold with Pf $3 \mathrm{~d} 7$ extract and 2.30-fold with Pf dd2 extract after a 24-hour co-incubation (Figure 6D and $\mathrm{E}$ ).

\section{Pc infection might activate the NF-KB signaling pathway in latently infected CD4+ $T$ cells}

Given that previous studies demonstrated that NF- $\mathrm{kB}$ activation was associated with provirus reactivation $[26,27]$, we investigated NF- $\kappa B$ translocation in monkey PBMCs in selected phases. This experiment used immunofluorescence confocal microscopy to assess the activation level of NF- $\kappa B$. The percentage of NF- $\kappa B+$ cells was significantly higher in the PBMCs of monkeys in the ART + Pc group during Plasmodium infection compared with the percentage in the ART group (means of 16.23\% and $9.69 \%$, respectively; $P<0.001$; Figure $7 \mathrm{~A}$ and $\mathrm{B}$ ). This result suggested that the NF-kB signaling pathway
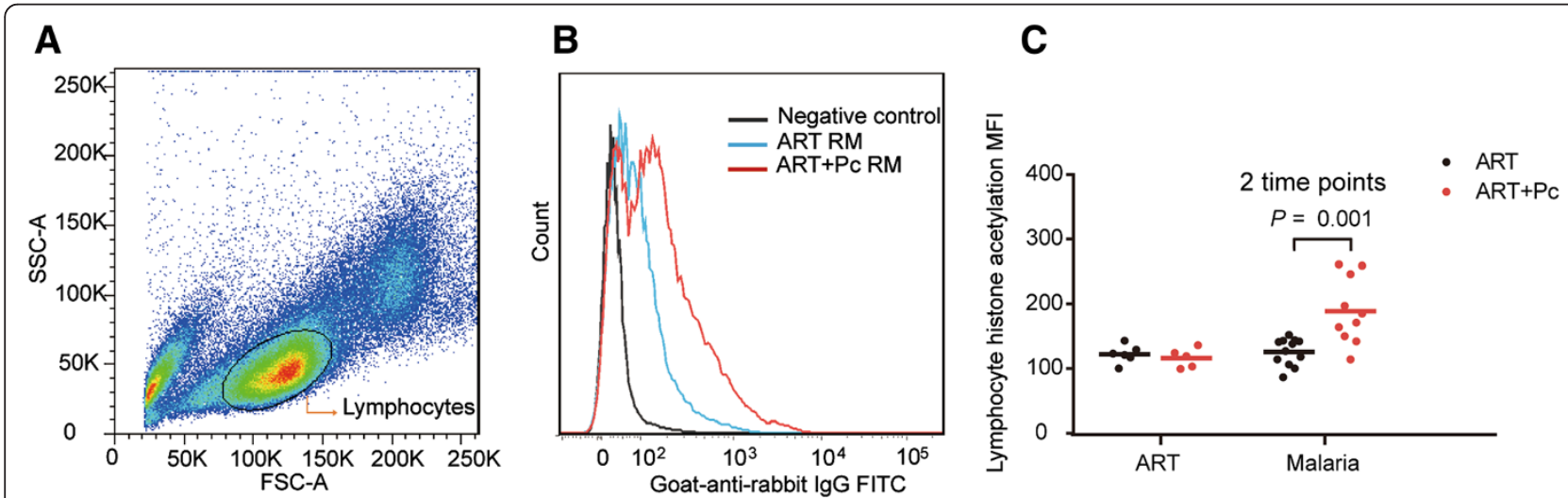

Figure 5 Flow cytometric quantitation of the histone acetylation levels in lymphocytes from different phases in the two groups of monkeys. (A) Lymphocytes gated by size on a forward scatter vs. side scatter plot. (B) Two monkeys were selected from different groups for representative flow cytometric analyses of different histone acetylation levels. The acetylated histone levels of the gated cells were analyzed by measuring the fluorescence intensity of these cells. The figure presents the difference in the lymphocytes' acetylation levels in the different groups at week 54 (5 weeks after PC infection). (C) Higher histone acetylation levels were observed in lymphocytes in the ART + Pc group during Pc infection (MFI of $188.90 \pm 51.33$ at week 54 vs. $125.96 \pm 20.80$ at week 57). MFI values from weeks 54 and 57 in the same group were combined to examine the difference in acetylated histone levels between the two groups during the malaria phase. The Mann-Whitney $U$ test was utilized for statistical analyses. The data are shown as the mean \pm SD. 


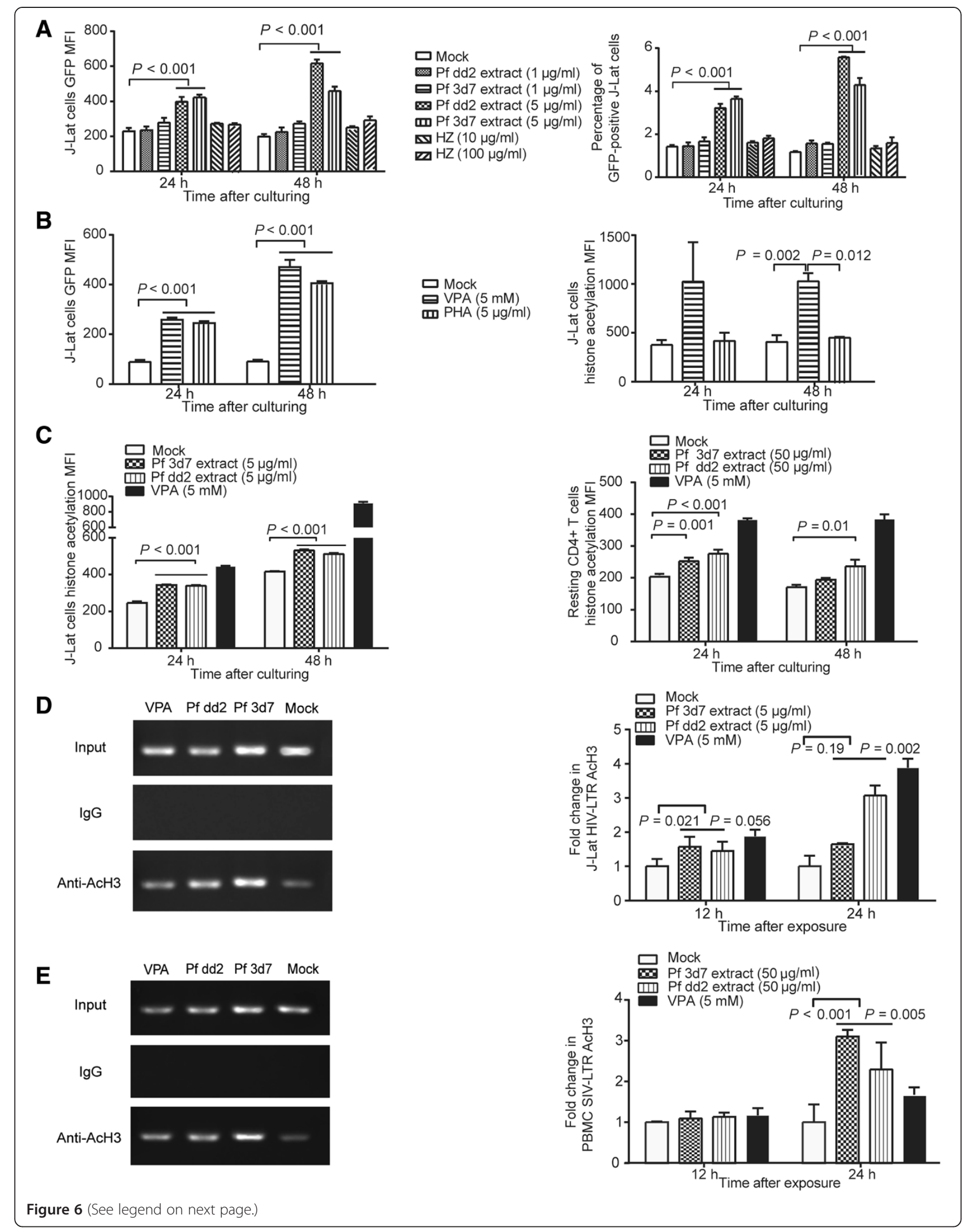


(See figure on previous page.)

Figure $\mathbf{6}$ In vitro assays measuring activation and histone acetylation of the HIV-1 or SIV promoter by Pf extracts. (A-B) The effects of the synergistic activation of the HIV-1 promoter were determined by quantifying GFP-positive cells using flow cytometry 24 or 48 hours after treatment. (A) In total, $5 \mathrm{\mu g} / \mathrm{ml}$ Pf soluble extract induced HIV-1 promoter activation in J-Lat cells, leading to GFP expression. (B) Both PHA and VPA induced activation of the HIV-1 promoter in J-Lat cells and subsequent GFP expression. In contrast, PHA did not induce increased levels of histone acetylation in J-Lat cells, whereas VPA induced histone acetylation. (C) 5 Hg/ml Plasmodium soluble extract increased histone acetylation levels in J-Lat cells, and $50 \mu \mathrm{g} / \mathrm{ml}$ Plasmodium soluble extract was sufficient to induce increased levels of histone acetylation in resting CD4+ T cells. This result was obtained from FACS assays. (D-E) Histone acetylation modifications in the HIV-1 LTR and SIV LTR promoters induced by Plasmodium soluble extract. Chromatin fragments from J-Lat cells or monkey PBMCs cultured for 24 hours with or without Plasmodium soluble extract or VPA were immunoprecipitated with anti-ACH3 or with normal rabbit serum (IgG) as a control. PCR was then used to amplify the DNA isolated from the immunoprecipitated chromatin. The relative dilution ratio of input/chip was 1.33. (D) Pf soluble extract induced an increase in the histone acetylation levels in the HIV-1 LTR. (E) Pf soluble extract induced an increase in the histone acetylation levels in the SIV LTR. The left panels of D and E show semi-quantitative results based on PCR products using input DNA, normal lgG control product or 24-hour CHIP product as the template. The data in this figure are presented as the means, and the error bars indicate the SD. One-way ANOVA was used to compare the variables in this figure.

might participate in the latent virus reactivation induced by malaria. An in vitro culture assay also indicated that $5 \mu \mathrm{g} / \mathrm{ml}$ or $50 \mu \mathrm{g} / \mathrm{ml}$ Plasmodium extract could induce NF- $\mathrm{kB}$ activation in J-Lat cells and monkey PBMCs (Figure $7 \mathrm{C}$ and D).
Memory CD4+ T cell activation, apoptosis and latent virus reactivation induced by $\mathrm{Pc}$ infection were partly associated with Plasmodium extract stimulation Our in vivo study showed that Plasmodium infection caused CD4+ T cell activation and might have led to the

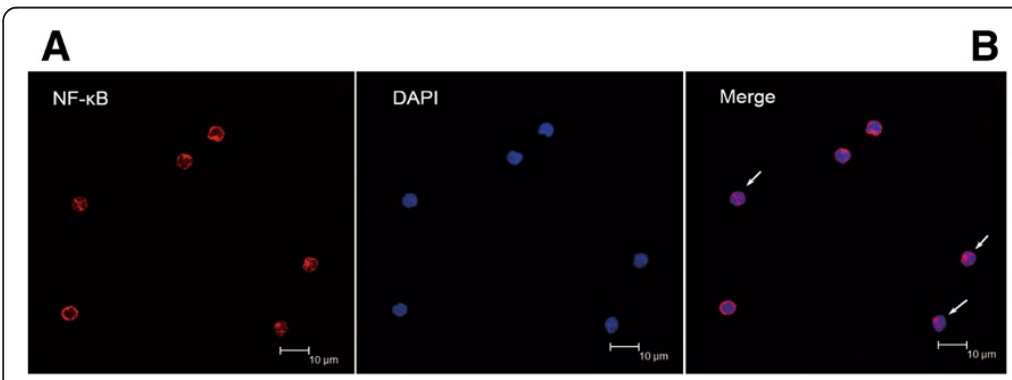

B

C

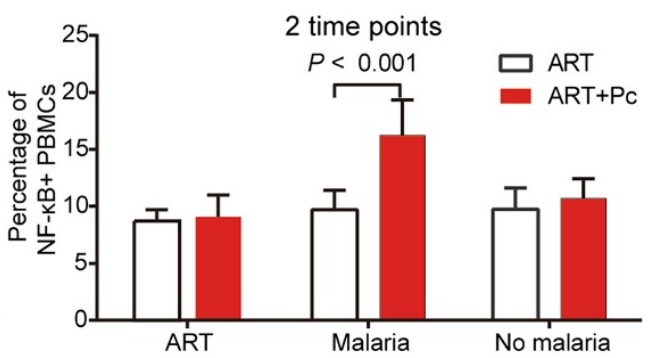

D
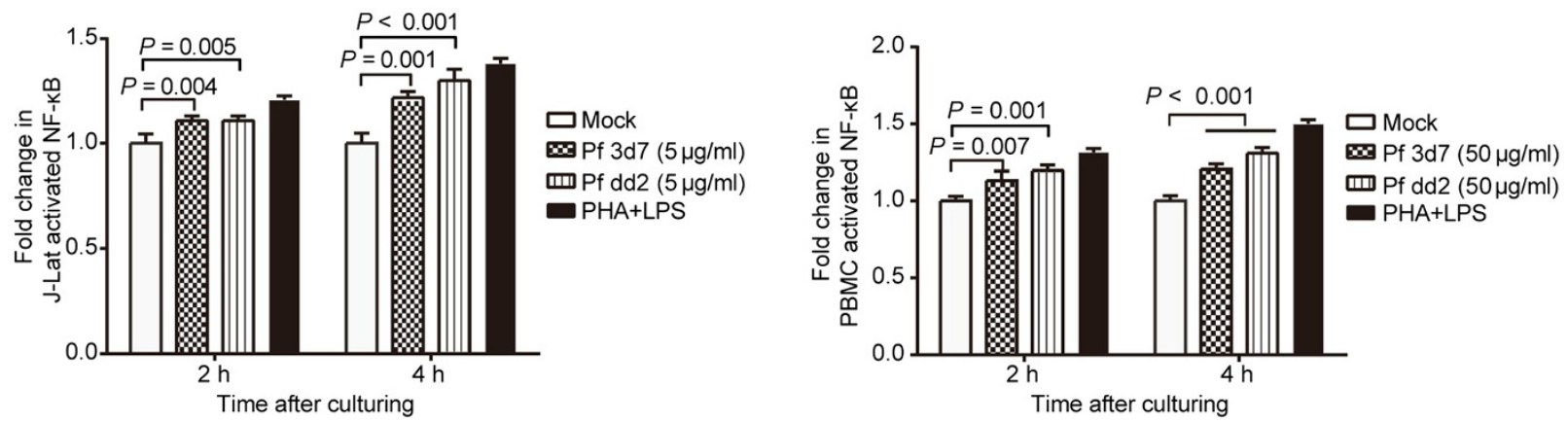

Figure $\mathbf{7}$ In vivo and in vitro assays for NF-KB activation. (A-B) An in vivo assay as performed to measure NF-KB activation levels during malaria infection. In particular, PBMCs were isolated from monkeys in the two groups at different time points for each phase. We counted the cells with NF-kB nuclear staining and classified them as cells with NF-KB activation. (A) NF-kB nuclear transport was measured by immunofluorescence to determine the activation of NF-KB in PBMCs. DAPI staining was used to identify the nuclear region to assess gross cell morphology. The white arrows show the NF-kB-positive nuclei in PBMCs. These cells were considered to contain activated NF-KB. (B) The ART + PC group maintained higher levels of NF-kB activation in PBMCs during malaria infection, as indicated by the percentages of NF-KB-positive nuclei in the PBMCs (16.23 $\pm 3.12 \%$ vs. $9.69 \pm 1.74 \%$ ). The data in this figure are presented as the means, and the error bars show the SD. (C-D) In vitro assays were performed to detect specific factors associated with malaria that activate NF-kB. PBMCs isolated from monkeys were stimulated with Pf extract or $25 \mathrm{ng} / \mathrm{ml}$ PHA plus $1 \mu \mathrm{g} / \mathrm{ml} \mathrm{LPS}$. NF-kB activation in the cells was then measured by ELISA. (C) Pf soluble extract induced an increase in activated NF-KB in J-Lat cells at 5 Mg/ml after a 2- or 4-hour incubation. (D) Pf soluble extract induced an increase in activated NF-kB in RM PBMCs at 50 $\mu \mathrm{g} / \mathrm{ml}$ after a 2- or 4-hour incubation. The percentages of NF-KB+ PBMCs at different time points of the same phase in the same group were combined for statistical analyses. The Mann-Whitney $U$ test was utilized to examine the difference in this parameter between the two groups. One-way ANOVA was used to compare the variables in C and D. The data in this figure are presented as the means, and the error bars indicate the SD. 
apoptosis of memory CD4+ T cells and a decrease in the iDNA load in PBMCs. The in vitro study also showed that Plasmodium extract could activate latently infected J-Lat 10.6 cells and cause the expression of latent virus (Figure 6A). To test the potency of Plasmodium extract in activating latently SIV-infected memory CD4+ T cells and inducing the apoptosis of these cells, we performed an in vitro assay in which PBMCs from a chronically SIV-infected monkey were treated with different concentrations of $\mathrm{Pf} 3 \mathrm{~d} 7$ or $\mathrm{dd} 2$ extract.

Figure $8 \mathrm{~A}$ and $\mathrm{B}$ show the potency of Pf $3 \mathrm{~d} 7$ extract in inducing the activation and apoptosis of monkey memory CD4+ T cells. The results showed that Pf extract could induce the apoptosis of memory CD4+ T cells and the activation of these cells. Specifically, more expression of the activation marker CD38 and HLA-DR was found after co-incubation with Pf extract (Figure 8A and B). Correlation analysis showed that the apoptosis of memory CD4 $+\mathrm{T}$ cells positively correlated with the activation level of these cells (Figure $8 \mathrm{C}$ ). Pf dd2 extract had similar potency in inducing the activation and apoptosis of monkey memory CD4+ $\mathrm{T}$ cells (data not shown). In addition, more expression of the SIV antigen $\mathrm{p} 27$ protein was induced after 8 days of culture with Pf extract (Figure 8D).

\section{Discussion}

Because malaria infection can induce CD4+ T cell activation and lead to the replication of HIV-1 in patients without ART [9], we postulated that malaria might activate resting CD4+ T cells, thereby promoting HIV-1 transcription and replication. This viral reactivation would then purge the HIV-1 reservoir in patients undergoing ART. We utilized a monkey model to test this hypothesis.

Rhesus macaques provide an ideal model for HIV-1 and malaria infection in humans [28-30]. SIV-infected rhesus macaques have revealed key aspects of HIV-1 pathogenesis, such as virus transmission, early post-infection events, the sites of viral replication, CD4+ T cell depletion, and virus and cell turnover [31], and these animals have been utilized in studies of viral reservoirs [16]. Compared with Chinese rhesus macaques, the Indian rhesus macaque model has limitations [32,33]; SIV pathogenesis in Chinese rhesus macaques more closely resembles HIV-1 infections in humans [34]. Beyond P. cynomolgi (Pc), two other malaria parasites, Plasmodium knowlesi and Plasmodium coatneyi, which can also infect rhesus macaques, are fulminating in rhesus macaques and nearly always result in death [35]. Thus, we utilized Pc and SIVmac251 coinfection in Chinese rhesus macaques to mimic HIV-1 and malaria co-infection in humans.

Malaria infection can increase the plasma viral load in HIV-1-infected individuals and in monkey models without ART $[9,14]$. In the present study, the ART + Pc group showed a $0.27-\log$ higher plasma viral load during malaria infection compared with the load in the ART group (2.01 $\log$ vs. $1.74 \log ;=0.090$; Additional file 1: Figure S1D). Because the iDNA level in PBMCs was lower in the ART + Pc group during malaria infection, this small change in plasma virus levels might not have been derived from viral replication in pre-existing activated CD4+ T cells or in newly infected CD4+ T cells, which are both susceptible to SIV because of the higher level of CCR5 expression on CD4+ T cells (Additional file 2: Figure S2D). This result also suggested that the ART regimen in this study effectively blocked SIV entry into these susceptible cells. A reasonable explanation is that this small increase in virus levels might have been derived from the activation of latently infected cells, which was reflected by our in vivo finding that malaria increased the activation level of CD4+ T cells (Figure 4A) and our in vitro finding that Plasmodium extract could induce activation of the main cellular reservoir, the memory CD4 + T cells (Figure 8B). The higher levels of IFN- $\gamma$ activity (represented by higher levels of plasma neopterin) induced by malaria also indicated immune system and $\mathrm{T}$ cell activation [13]. The higher levels of neopterin induced by malaria especially indicated the activation of macrophages [36], which may be more critical in the process of SIV reservoir purging because Van der Sluis et al. have shown that APCs such as myeloid dendritic cells can activate latent $\mathrm{T}$ cells more than other T cell activators do [37]. A correlation analysis of plasma neopterin and the activation level of CD4+ T cells might also have uncovered this phenomenon (Additional file 2: Figure S2D). In contrast to neopterin, neither the expression of the other cytokines tested, including IL-2, IL-6, IL-7 and TNF- $\alpha$, nor their activities increased during malaria infection under ART (i.e., there were no differences between the two groups; Additional file 2: Figure S2A), indicating that ART potentially alters the interaction of SIV and the malaria parasite in vivo.

The activation of resting CD4+ T cells could facilitate the apoptosis of these cells [38,39]. Malaria infection specifically induces apoptosis in mononuclear cells, including memory $\mathrm{T}$ cells, and contributes to reduction of the immune response to critical antigens [40]. This effect was also observed in the ART + Pc group (Figure 3A and B) and in our in vitro assay (Figure 8A). However, due to the relatively small number of animals in the present study, we did not observe a significant effect of malaria on CD4+ $\mathrm{T}_{\mathrm{CM}}$ cell apoptosis, but monkeys that were co-infected with malaria did maintain a relatively higher level of apoptotic CD4 $+\mathrm{T}_{\mathrm{CM}}$ cells (Figure $3 \mathrm{~A}$ ). Moreover, the effect of malaria on CD4+ $\mathrm{T}_{\mathrm{EM}}$ cell apoptosis was significant (Figure 3B). We also observed significantly high levels of apoptotic memory cells induced by Pf extract in our in vitro study (Figure $8 \mathrm{~A}$ ). These results indicated that malaria did induce the apoptosis of memory CD4+ T cells, which were the main cellular reservoir of SIV. It is 


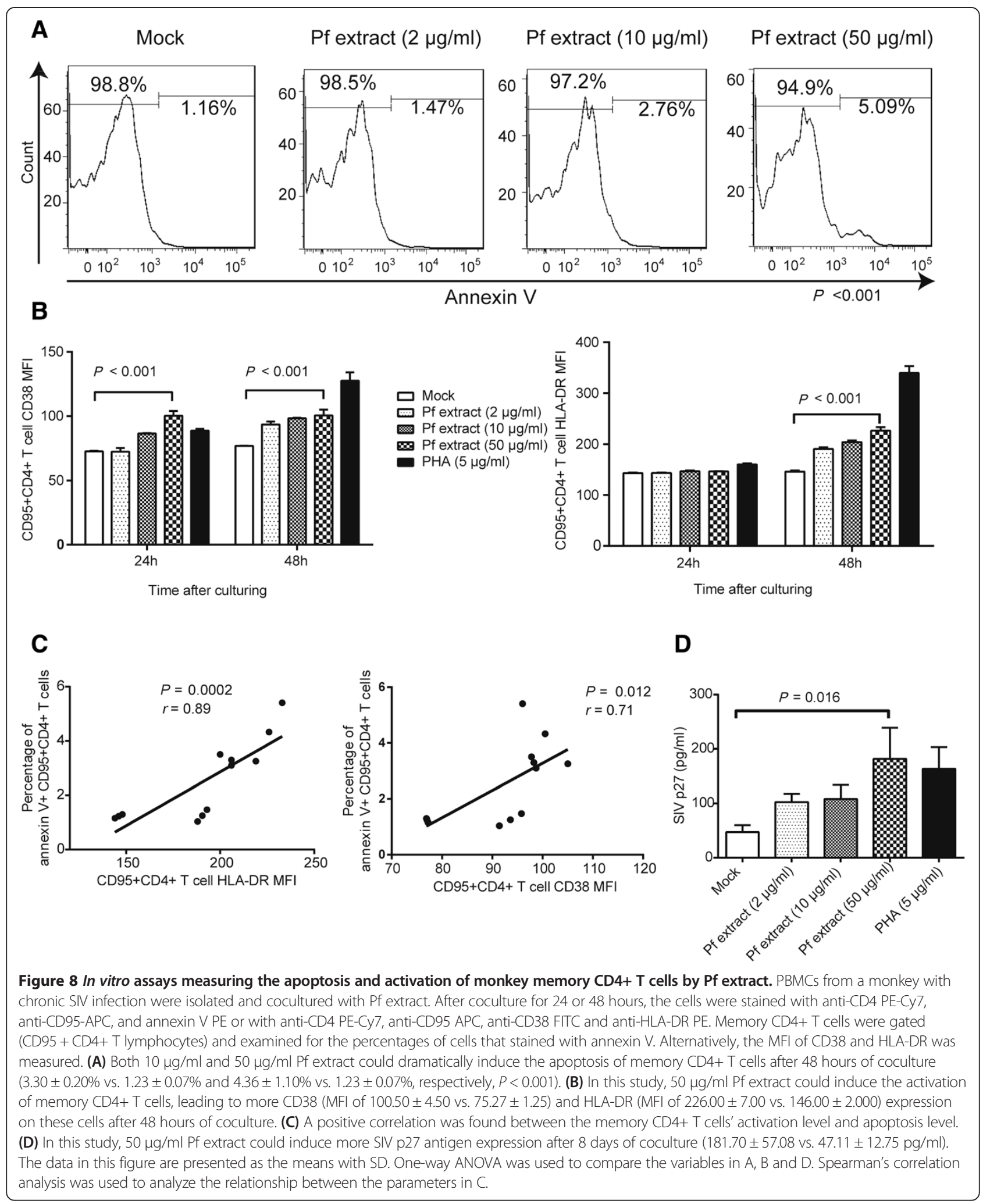

possible that several "long-lived" $\mathrm{T}_{\mathrm{CM}}$ cells can transition into "short-lived" $\mathrm{T}_{\mathrm{EM}}$ cells that are more susceptible to apoptotic signals [41]. Thus, a significantly higher level of apoptotic $\mathrm{T}_{\mathrm{EM}}$ cells was observed, but the final outcome might have been the result of the "indirect apoptosis" of $\mathrm{T}_{\mathrm{CM}}$ cells. All of these effects could be associated with the 
expression of the activation markers HLA-DR and CD38 on CD4+ T cells, which reflects the activation level of these cells (Figure 4A-C). Furthermore, the reduction of the SIV iDNA load in PBMCs was significantly negatively correlated with increased levels of apoptotic CD4+ $\mathrm{T}_{\mathrm{CM}}$ cells and the proportion of HLA-DR + CD38 + CD4+ T cells during malaria infection (Figures $3 \mathrm{C}$ and $4 \mathrm{D}$ ). We also found that the SIV iDNA load in PBMCs negatively correlated with increased levels of apoptotic CD4+ $\mathrm{T}_{\mathrm{EM}}$ cells although no significant and this may due to the small number of animals in present study (Figure 3D). These results indicated that malaria infection activated and induced the apoptosis of CD4+ T cells, including memory cells, thereby leading to the reduction of the SIV reservoirs. The in vitro study also demonstrated that Pf extract could activate the memory $\mathrm{CD} 4+\mathrm{T}$ cells, along with the production of virion, and could induce the apoptosis of these cells, suggesting that malaria-induced reservoir purging was partly related to the Plasmodium itself. This result was partly consistent with a report by Froebel et al., showing that malaria antigens could reactivate the replication of endogenous HIV in cells from HIV-infected adults [13].

Histone acetylation in cells is an epigenetic change that can induce transcriptional activation of HIV-1 provirus and lead to reservoir purging [25,42]. In the present study, higher levels of histone acetylation in the PBLs of Pcinfected monkeys were observed. Activation of NF- $\mathrm{kB}$ is also associated with provirus reactivation [27]; we observed more NF- $\kappa B$ translocation in PBMCs from the Pc-infected monkeys. This result was consistent with Chuchard's report, which showed that PBMCs in malaria patients maintained higher levels of NF- $\mathrm{kB}$ activation [43]. Our in vitro studies also confirmed that Pf extracts could induce histone acetylation in resting $\mathrm{CD} 4+\mathrm{T}$ cells and in latently HIV-1-infected cells (J-Lat cells) and could activate NF-kB signaling in monkey PBMCs and in J-Lat cells. Histone acetylation in cells is not necessarily associated with the global activation of host cells, which is similar to the situation induced by the histone deacetylase (HDAC) inhibitor VPA [44]. However, reactivation of latent virus would lead to antigen expression on host cells, which would induce antigen-specific cytotoxic lymphocyte responses that would kill the infected cells [4]. Therefore, histone acetylation and NF- $\kappa B$ activation may also play important roles in the reduction of the SIV reservoir.

In the present study, we observed that malaria caused epigenetic changes in monkeys and that this phenomenon was related to the Plasmodium itself. This result was unexpected. In particular, many environmental factors, such as exercise, diet and medications, can cause epigenetic and developmental epigenetic changes [45,46], whereas our results indicated that a type of microorganism infection can cause such changes and this was related to its extract. Further experiments demonstrated that J-Lat cells and primary monkey cells had different response patterns in the presence of Pf extract and that $5 \mu \mathrm{g} / \mathrm{ml} \mathrm{Pf}$ extract could induce a considerable increase in histone acetylation in J-Lat cells, whereas more Pf extract was needed to induce an increase in histone acetylation in monkey resting CD4+ T cells (Additional file 3: Figure S3). The differences in patterns might be attributable to the different proliferation levels of these two types of cells; J-Lat cells, which are derived from Jurkat cells, are actively proliferating tumor cells, and primary monkey cells are non-actively proliferating cells. The different cell cycle patterns in these two types of cells may cause different sensitivities to Pf extract, as it has been shown that different cell cycle patterns may lead to different sensitivities to certain factors $[47,48]$. The present study also showed that the increase in the histone acetylation level induced by Pf extract was not due to regulation of HDAC, which has been shown to participate in regulating the histone acetylation level. This finding indicated that the mechanism of Plasmodium inducing histone acetylation was not similar to that of an HDAC inhibitor (Additional file 4: Figure S4). However, the exact mechanism needs to be studied further and in depth. We do not know whether this phenomenon was Plasmodium specific, but lipopolysaccharide (LPS) did not induce an increased level of histone acetylation in primary monkey cells (Additional file 5: Figure S5), indicating that certain factors related to bacteria might not be associated with this phenomenon.

In the present study, we did not observe a delay in viral rebound in the ART + Pc group compared with the ART group when ART was terminated at week 75 after SIV inoculation (Additional file 1: Figure S1). The re-emergence or rebound of plasma viremia has also previously been observed following the cessation of ART, despite profoundly low HIV-1 reservoir levels [49]. Possible reasons for this observation in rhesus macaques include the following. First, although the cellular reservoir of SIV decreased during malaria infection, the frequency of resting CD4+ T cells harboring replication-competent SIV remained a large burden for the monkeys. Second, the possibility of the existence of low levels of SIV replication, the persistence of the virus in lymphoid tissues or cryptic viral replication in anatomical reservoirs in macaques treated with ART cannot be eliminated due to the efficiency of the ART regimen.

\section{Conclusions}

Altogether, our results indicate that malaria reduced the volume of the SIV reservoir in monkeys that underwent ART. We have highlighted the apoptosis of memory $\mathrm{CD} 4+\mathrm{T}$ cells during Pc infection, which is a potential outcome of the activation of these cells induced by malaria. Our in vivo and in vitro results indicate that histone acetylation and NF- $\mathrm{kB}$ activation in resting CD4+ T cells may also play important roles. 
As more HIV-1-infected individuals in malaria-endemic areas receive ART, physicians and researchers should pay attention to the impact of malaria on the viral reservoir of these individuals. For example, repeated or longer courses of malaria infection may occur and more profoundly reduce the volume of the viral reservoir in HIV-1-infected individuals who are receiving effective ART in areas that are endemic for both HIV-1 and malaria. Several of these patients may experience virologic benefits. In addition, based on our previous study [50], modified malaria parasites should be explored as vectors for therapeutic HIV-1 vaccine development.

\section{Methods}

\section{Animals and study design}

The animals were housed and fed according to regulations established by the Guide for the Care and Use of Laboratory Animals and the Animal Welfare Act at the Non-human Primate Animal Center of the Guangzhou Institutes of Biomedicine and Health (GIBH). The animal experiments performed in this study were approved by the GIBH Institutional Animal Care and Use Committee (IACUC) (approval ID 2010008). Figure 1 shows the study design. All monkeys were treated with ART 15 weeks after SIV inoculation. The treatment regimen included $30 \mathrm{mg} / \mathrm{kg}$ 9-R-(2-phosphonomethoxypropyl) adenine (PMPA) and $20 \mathrm{mg} / \mathrm{kg}$ emtricitabine (FTC), administered once daily intramuscularly (i.m.). Then, $100 \mathrm{mg}$ raltegravir (an integrase inhibitor) was added orally twice per day at week 36 . At week 49, the monkeys in the ART + Pc group were intravenously inoculated with $2.38 \times 10^{7}$ Pc-infected red blood cells (RBCs). As controls, monkeys in the ART group were inoculated with $2.38 \times 10^{7}$ normal RBCs. The Pc infection was terminated at week 66 by oral chloroquine administration, and ART was terminated at week 75 .

\section{Plasma SIV levels}

The levels of plasma SIV RNA were measured by quantitative reverse transcriptase PCR (qRT-PCR), as previously described [51]. The number of SIV RNA copies was calculated from a regression curve derived from RNA transcript standards. This value was divided by the volume of the extracted plasma specimen to obtain a value in units of SIV RNA copy equivalents/ml of plasma. In brief, $2000 \mu \mathrm{l}$ plasma was centrifuged at $21,000 \times \mathrm{g}$ for 3 hours at $4^{\circ} \mathrm{C}$, and $1850 \mu \mathrm{l}$ supernatant was removed. The virus pellet was then resuspended completely by vigorous vortexing and stored at $-80^{\circ} \mathrm{C}$ for RNA isolation. RNA was isolated using the NucleoSpin viral RNA isolation kit (MACHEREYNAGEL, Duren, Germany) according to the manufacturer's instructions, except that the virus was incubated in lysis buffer for 10 minutes at room temperature. The RNA was eluted in $50 \mu \mathrm{l}$ RNase-free $\mathrm{H}_{2} \mathrm{O}$ and frozen in aliquots at $-80^{\circ} \mathrm{C}$ for subsequent qRT-PCR.
Modified real-time RT-PCR was performed to measure the conserved region of gag in the viral RNA, as described by Hofmann-Lehmann [52]. The primers and probe specific for the conserved gag region of SIVmac251 were as follows: forward, Alu1217, GCAGAGGAGGAAATTAC CCAG; reverse, SIVgag, ACAATTTTACCCAGGCATT TAATGTT; and probe Alu1217-P6-carboxyfluorescein, (FAM)-TCGGGCTTAATGGCAGGTGGACA-BHQ1. The reactions were performed in $25 \mu \mathrm{l}$ volumes containing $12.5 \mu \mathrm{l}$ RNA-direct Realtime PCR Master Mix (Toyobo, Shanghai, China), $3 \mathrm{mM} \mathrm{Mn}(\mathrm{OAc})_{2}, 300 \mathrm{nM}$ forward and reverse primers, $100 \mathrm{nM}$ probe and $5 \mu$ template. The thermal cycling conditions consisted of 30 seconds at $90^{\circ} \mathrm{C}$, 20 minutes at $61^{\circ} \mathrm{C}$, and 30 seconds at $95^{\circ} \mathrm{C}$, followed by 45 cycles of 1 seconds at $95^{\circ} \mathrm{C}, 45$ seconds at $60^{\circ} \mathrm{C}$ and a plate read. The kinetic PCR amplification data were analyzed using Bio-Rad CFX Manager software. A standard curve for the viral RNA was then prepared using serial dilutions of a synthetic gag transcript in $\mathrm{H}_{2} \mathrm{O}$ containing $30 \mu \mathrm{g} / \mathrm{ml}$ transfer RNA from Escherichia coli (Sigma). This 544 bp RNA was transcribed in vitro using SP6 RNA Polymerase (Takara, Dalian, China) and an EcoRI-digested PMD-20 T plasmid into which a 461 bp fragment of SIV gag was inserted. The numbers of RNA copies were calculated from the concentration determined by the absorbance at $260 \mathrm{~nm}$. Three replicate reactions were performed for the samples and standard. The numbers of copies of SIV RNA in the samples were calculated by interpolation of the experimentally determined quantification cycle $(\mathrm{Cq})$ value for the test sample using the transcript-derived linear regression as a standard curve.

\section{Real-time qPCR for SIV iDNA in PBMCs}

The amount of SIV iDNA was quantified using modified Alu-PCR according to the method of Norio et al. [53]. The primers and probe for the first-round PCR were mAlu196 F20, CAGGAGAATCGCTTGAACCC; mAlu-228R19, GATCTCGGCTCACTGCAAC; and Alu1217-RArt, CAA TATCATACGCCGAGAAATGTTCTCGGGCTTAATGG. The reactions were performed in $70 \mu \mathrm{l}$ volumes containing $25 \mu \mathrm{l}$ Premix Ex Taq (Takara), $450 \mathrm{nM}$ each primer and $7 \mu \mathrm{l}$ template. We pre-amplified a $50 \mu \mathrm{l}$ reaction mixture under the following thermal cycling conditions: 60 seconds at $95^{\circ} \mathrm{C}$, followed by 12 cycles of 10 seconds at $98^{\circ} \mathrm{C}, 30 \mathrm{sec}-$ onds at $60^{\circ} \mathrm{C}$ and 5 minutes at $72^{\circ} \mathrm{C}$. The rest of the reaction mixture was stored at $4^{\circ} \mathrm{C}$ as "non-pre-amplified" samples. The second-round real-time quantitative multiplex PCR was performed using $2 \mu$ of the material from the pre-amplified or matched mixture of "non-preamplified" samples. The sequences of the primers and probes were as follows: GAPDH-cF, CCCCATAGGCGAGA TCCC; GAPDH-cR, CCTCCTGCACTCACCCC; GAPDHcP, HEX-CCACGACGTACTCAGCGCCAGCAT-BQ1; Alu 1217-F, GCAGAGGAGGAAATTACCCAG; Alu1217-Art, 
CAATATCATACGCCGAGAAATGT; and Alu1217-P, FAM-TCGGGCTTAATGGCAGGTGGACA-BQ1. The reactions were performed in $20 \mu \mathrm{l}$ volumes containing $10 \mu \mathrm{l}$ THUNDERBIRD Probe qPCR Mix (Toyobo), 300 nM GAPDH-cF and GAPDH-cR, 100 nM GAPDH-cP, $450 \mathrm{nM}$ Alu1217-F and Alu1217-Art, 150 nM Alu1217$\mathrm{P}$ and $2 \mu \mathrm{l}$ template. The thermal cycling conditions consisted of 60 seconds at $95^{\circ} \mathrm{C}$, followed by 45 cycles of 15 seconds at $95^{\circ} \mathrm{C}, 15$ seconds at $60^{\circ} \mathrm{C}$ and a plate read. The kinetic PCR amplification data were analyzed using Bio-Rad CFX Manager software. A standard curve for the viral DNA was prepared using serial dilutions of cellular DNA extracted from CEMss/SIV/rc cells diluted in $10^{4}$ cells/ $\mu$ l CEMss DNA. Three replicate reactions were performed for both species and the standard. The numbers of copies of SIV and cell genomes in the test samples were calculated by interpolation of the experimentally determined $\mathrm{Cq}$ value for the test sample using the linear regression as a standard curve. The calculated number of copy equivalents per reaction mixture is expressed as the number of SIV copies per $10^{5}$ cells.

\section{Measurement of the frequency of resting CD4+ T cells harboring replication-competent virus}

Macaque resting $\mathrm{CD} 4+\mathrm{T}$ cells were isolated as described elsewhere [30,54]. Briefly, macaque blood was centrifuged through discontinuous density gradients to obtain PBMCs using 95\% Lymphoprep (Fresenius Kabi Norge AS, Halden, Norway). The PBMCs were labeled with FITC-conjugated anti-CD4 and APC-conjugated antiHLA-DR (BD Biosciences, Franklin Lakes, USA) and sorted for small HLA-DR-CD4+ cells using a FACSAria II. Populations of small HLA-DR-CD4+ cells were isolated with $98-99 \%$ purity. The frequency of resting $\mathrm{CD} 4+\mathrm{T}$ cells harboring replication-competent virus was then measured using a co-culture assay in which resting $\mathrm{CD} 4+\mathrm{T}$ cells were cultured with the cell line CEM $\times$ 174. This co-culture both activated the macaques' resting CD4+ $\mathrm{T}$ cells through CD2-CD58 interactions and expanded virus released from latently infected cells that became activated, allowing quantification of the size of the reservoir, as previously described $[55,56]$. The resting CD4+ T cells were cultured in a fivefold dilution series in duplicate, ranging from $1 \times 10^{6}$ to $3.2 \times 10^{2}$ cells per well. The presence of replication-competent SIV was then determined by observing SIV outgrowth with p27 after 3 weeks of culture. The co-culture assays were set up in a limiting-dilution format, and the frequencies of resting $\mathrm{CD} 4+\mathrm{T}$ cells harboring replication-competent virus were determined using the maximum likelihood method, as previously described [56]. The lower limit of detection was 0.51 IUPM in the present study.
T cell assays, flow cytometry, and monoclonal antibodies (mAbs)

The following mAbs were used for flow cytometry: antiCD3 PerCP, anti-CD4 FITC, anti-CD4 PerCP, anti-CD4 PECy7, anti-CD8 PerCP, anti-CD8 APC-Cy7, anti-CD28 FITC, anti-CD95 APC, anti-CD195 (anti-CCR5) PE, antiKi67 PE, anti-HLA-DR APC, and anti-HLA-DR FITC (BD Biosciences). Additionally, annexin V PE was purchased from BD Biosciences, anti-CD8 APC and anti-CD8 PE were obtained from Beckman Coulter (CA, USA), and antiCD38 FITC was purchased from StemCell Technologies (Vancouver, Canada). Flow cytometry data were acquired on a FACSAria II (BD Biosciences). All data were analyzed using FlowJo software (Tree Star, Ashland, OR, USA).

\section{ELISA for plasma cytokines}

Plasma IL-2R, neopterin, IL-6, TNF- $\alpha$ and IL-7 concentrations were assayed by ELISA kits according to the manufacturers' instructions. The kits were obtained from BioLegend (for IL-2R), Groundwork Biotechnology Diagnosticate and Alpha Diagnostic International (for neopterin), Mabtech (for IL-6 and TNF- $\alpha$ ) and R\&D Systems (for IL-7). Each plasma sample was analyzed in triplicate.

\section{In vivo NF-KB activation and nuclear transport tests}

NF- $\mathrm{kB}$ activation and nuclear transport tests were performed using a Nuclear Translocation Assay Kit (catalog no. SN368, Beyotime, Beijing, China) according to the manufacturers' instructions. Briefly, PBMCs from monkeys were collected and then washed once with PBS. These cells were fixed, transferred to slides, and washed twice with PBS with Tween-20 (PBST). The cells on the slides were blocked using PBS with $8 \%$ BSA for 1 hour. Next, the cells were incubated with a rabbit anti-human NF-kB p65 antibody (Beyotime, Beijing, China) at $4^{\circ} \mathrm{C}$ overnight. The cells were then stained with a Cy3-labeled anti-rabbit antibody (Beyotime, Beijing, China), washed with PBST three times and stained with DAPI at room temperature for 10 minutes. Finally, the cells were washed with PBST three times and observed using a confocal microscope (ZEISS LSM 710). A total of 500 cells on each slide were counted. We specifically counted cells with NF- $\mathrm{kB}$ nuclear staining and classified them as cells with NF- $\mathrm{kB}$ activation.

\section{Measurement of global histone acetylation by flow cytometry} This assay was performed according to the method reported by Archin et al. [25]. Briefly, cells were fixed and permeabilized with Phosflow Fix Buffer I and Phosflow Perm Buffer II (BD Biosciences) according to the manufacturer's protocol. The cells were then washed in staining buffer (PBS with $2 \% \mathrm{FBS}$ and $0.1 \%$ sodium azide), blocked with $8 \%$ normal goat serum (Invitrogen), and incubated with anti-AcH3 (1:200 dilution; catalog no. 06-599, Millipore) or control rabbit IgG in blocking solution for 60 minutes at 
room temperature. Next, the cells were washed twice with staining buffer and incubated with goat-anti-rabbit IgG FITC- or Cy3-conjugated secondary antibody (1:200 dilution; Millipore) in staining buffer for 30 minutes at room temperature in the dark. Following a final wash, the cells were analyzed by flow cytometry using a FACSAria II flow cytometer and FlowJo software (Tree Star).

\section{In vitro experimental design, cells, culture conditions, and cell treatments}

Pf $3 \mathrm{~d} 7$ or $\mathrm{dd} 2$ extract or $\mathrm{HZ}$ was added to J-Lat cell cultures to monitor whether the treatment reactivated provirus expression, as indicated by increased GFP expression and induced histone acetylation or NF- $\mathrm{kB}$ activation. We also performed the same culture assays to monitor the effect of Pf extracts on resting CD4+ T cells or PBMCs from rhesus macaques. Pf extract preparation was performed using saponin to release parasites and an ultrasonic cell disruptor (Bioruptor UCD-300, Diagenode, Liège, Belgium) to extract. The concentration was measured based on the protein concentration. Plasmodium $\mathrm{HZ}$ extraction was performed as follows. Parasites were released from RBCs by $0.01 \%$ saponin lysis and were washed 5-8 times to remove RBC debris. Next, the parasites were lyophilized and extracted with chloroform-methanol $(2: 1 \mathrm{v} / \mathrm{v})$ to remove lipids and with chloroform-methanol-water (10:10:3 v/v) to remove GPIs. After drying, the residue was resuspended in $100 \mathrm{mM}$ Tris- $\mathrm{HCl}$ and $1 \mathrm{mM} \mathrm{CaCl}_{2}$ (pH 7.5) and digested with pronase to remove proteins and proteinlinked GPIs. The insoluble residue was extracted with $50 \mathrm{mM}$ sodium phosphate ( $\mathrm{pH} 7.2), 4 \mathrm{M}$ guanidine hydrochloride, and $0.5 \%$ Triton X-100 and was stirred overnight at $4^{\circ} \mathrm{C}$ to remove nucleic acids. The residue (insoluble $\mathrm{HZ}$ ) was recovered by centrifugation, washed three times with double-distilled water and once with 80\% 1-propanol, and then dried. The HZ was resuspended in PBS at a final concentration of $10 \mathrm{mg} / \mathrm{ml}$ and stored at $4^{\circ} \mathrm{C}$.

\section{Measurement of activated NF-KB by ELISA}

The expression of phospho-NF-kB p65 was tested using a sandwich ELISA kit (Cell Signaling, USA) according the manufacturer's instructions. Each sample was assessed in triplicate. Briefly, total protein was extracted from $2 \times 10^{6}$ cells/well with different treatments. The protein was then added to 96-well plates coated with mouse mAb, and the plates were incubated overnight at $4^{\circ} \mathrm{C}$. Next, a phosphoNF- $\mathrm{kB}$ p65 rabbit mAb was added, and the horseradish peroxidase (HRP) method was used for detection. Each assay was performed in triplicate.

\section{Measurement of the histone acetylation levels of the HIV-1 or SIV LTR by ChIP}

ChIP analysis was performed according to the online protocol provided by Millipore and procedures described elsewhere [57]. Briefly, cells were cross-linked with $1 \%$ formaldehyde for 10 minutes at $37^{\circ} \mathrm{C}$; cross-linking was then stopped by the addition of a glycine solution. The cells were washed twice in ice-cold PBS with $1 \mathrm{mM}$ PMSF, resuspended in sodium dodecyl sulfate (SDS) lysis buffer containing $1 \mathrm{mM}$ PMSF and incubated for 10 minutes on ice. The lysates were sonicated to produce DNA fragments with an average length of 500-1000 bp using a Bioruptor D-300 sonicator (Diagenode). The chromatin fragments from J-Lat 10.6 cells (full-length clones) or rhesus macaques' PBMCs with different treatments were then diluted tenfold with immunoprecipitation (IP) dilution buffer. After pre-clearing with Protein $G$ agarose for 30 minutes at $4^{\circ} \mathrm{C}$ with agitation, the material was immunoprecipitated with $2 \mu \mathrm{g}$ anti-AcH3 (catalog no. 17-615, Millipore) or preimmune rabbit IgG (Millipore) via incubation overnight at $4^{\circ} \mathrm{C}$ with rotation. To collect the immune complexes, appropriate amounts of Protein $\mathrm{G}$ agarose were added to each reaction mixture, and the resulting mixtures were rotated for 60 minutes at $4^{\circ} \mathrm{C}$. The beads were centrifuged and then sequentially washed for 5 minutes at $4^{\circ} \mathrm{C}$ with each of the following: low-salt immune-complex wash buffer, high-salt immune-complex wash buffer, $\mathrm{LiCl}$ immunecomplex wash buffer, and Tris-EDTA buffer. After the immune complexes were eluted by incubation in elution buffer (1\% SDS and $0.1 \mathrm{M} \mathrm{NaHCO} 3$ ), the supernatants were isolated and further incubated for 4 hours at $65^{\circ} \mathrm{C}$ with appropriate $\mathrm{NaCl}$ concentrations to reverse the crosslinking. Input controls were treated in the same manner. After reverse cross-linking, DNA was purified using an Axygen DNA purification kit (Corning Life Sciences, USA). PCR was performed using HIV-1 or SIV promoter primers spanning the nuc-1 region of the LTR. The primers for the HIV-1 LTR or SIV LTR were as follows: LTR-109 F (5' -TACAAGGGACTTTCCGCTGG-3') and LTR + 82R (5' -AGCTTTATTGAGGCTTAAGC-3'). The DNA products of ChIP were quantitated by real-time PCR (Bio-Rad CFX96, USA). The phosphorimager data related to the amounts of PCR product obtained from the immunoprecipitated chromatin samples were then compared with the amounts of PCR product obtained for the input DNA. The percent of immunoprecipitated LTR was determined by comparing the cycle threshold values of each reaction with a standard curve generated from the input DNA, and these data are reported as the percent of input.

\section{HDAC activity assay}

An HDAC activity assay was performed using an HDAC Activity Colorimetric Assay Kit (BioVision, Palo Alto, USA) according to the manufacturer's instructions. Each sample was assessed in triplicate. Briefly, total protein was extracted from $2 \times 10^{6}$ cells/well with different treatments, with a final volume of $200 \mu \mathrm{l}$ in sterile water. Appropriate volumes of protein solution were then added 
to 96-well plates containing an appropriate HDAC substrate, HDAC assay buffer and a deacetylated standard; mixed thoroughly; and incubated in $37^{\circ} \mathrm{C}$ for 1 hour. Finally, lysine developer was added to the wells and incubated in $37^{\circ} \mathrm{C}$ for 30 minutes to produce a chromophore.

\section{SIV p27 antigen assay}

An SIV p27 antigen assay was performed using an ELISA kit (catalog no. 5436, Advanced Bioscience Laboratories, Kensington, USA) according to the manufacturer's instructions. Briefly, cell culture supernatant was first treated with phosphate buffer with $2.5 \%$ Triton-X-100 to release SIV antigen and then added to 96-well plates coated with a murine mAb to SIV p27. These plates were incubated at $37^{\circ} \mathrm{C}$ for 1 hour. Next, HRP-labeled mouse mAb to SIV p27 was added and incubated at $37^{\circ} \mathrm{C}$ for 1 hour, and the HRP method was used for detection. Each assay was performed in triplicate.

\section{Statistical analysis}

Variables in the same phase and group were combined to form a dataset for statistical analysis. Spearman's correlation analysis was used to analyze the relationship between the parameters tested. The Mann-Whitney $U$ test was used to analyze differences between variables obtained from the in vivo tests. Fisher's exact test was used for comparisons of IUPM under the detection limit, i.e., when the assay could not generate an exact value. One-way ANOVA was used in comparisons of variables for in vitro assays. $\mathrm{P}<0.05$ was considered significant. GraphPad Prism 6 (GraphPad Software) was used for graphing. Statistical analyses were performed using SPSS 16. Empower (R) (www. empowerstats.com, X\&Y Solutions, Inc., Boston, MA) and $\mathrm{R}$ (http://www.R-project.org) were used for smooth curve fitting.

\section{Additional files}

Additional file 1: Figure S1. Dynamic changes in plasma SIV viral loads and certain immunological parameters in the two groups of monkeys during this study. (A-C) Inoculation with SIV resulted in a peak plasma viral load between $10^{4}$ and $10^{7}$ copies of viral RNA $/ \mathrm{ml}$ at week 2 , and a viral set point ranging from $10^{3}-10^{6}$ copies of viral RNA $/ \mathrm{ml}$ of plasma was established at approximately 12-15 weeks. The monkeys showed a decay of viremia to below the limit of detection (100 RNA copies $/ \mathrm{ml}$ ) after approximately 20 weeks of ART. (A) The plasma viral load of the monkeys during this study. The line shows the median plasma viral load in both groups during the study. (B) The plasma viral load of each monkey in the ART group. (C) The plasma viral load of each monkey in the ART + PC group. The lines in Additional file 1: Figure S1A, B and C show the dynamic changes in the plasma viral load in each monkey during the study. (D) The plasma viral load in each phase. Malaria induced a small increase (not significant) in the plasma viral load under ART. The horizontal lines indicate mean values. (E-F) Peripheral blood CD4+ T cells in the two groups of monkeys. The number of CD4+ T cells dramatically decreased during acute SIV infection, along with an increase in CD8+ T cells, but both recovered to baseline levels after control of viral replication. (G-H) SIV infection induced a degree of immune activation, as represented by an increased proportion of
HLA-DR+CD4+ T cells and HLA-DR+CD8+ T cells. The data in Figure S1E-H are shown as the means and SD values. Plasma viral loads from different time points in the same group and phase were combined for statistical analyses. The Mann-Whitney $U$ test was utilized.

Additional file 2: Figure S2. The impact of malaria on certain parameters related to activation of the immune system and CD4+ T cells. (A) The concentrations of plasma cytokines and activity markers, including IL-2R, IL-7, IL-6 and TNF-a, did not increase during malaria infection under ART. (B) The ART + PC group displayed a significantly higher concentration of plasma neopterin during malaria infection. (C) PC infection induced the expression of CCR5 in CD4+ T cells, which also indicated activation of these cells. (D) A significant positive correlation was found between CD4+ T cell activation levels and the plasma neopterin concentration. Parameters from different time points in the same group and phase were combined for statistical analyses. The Mann-Whitney $U$ test was utilized. Spearman's correlation analysis was used to analyze the relationship.

Additional file 3: Figure S3. The dose response to Pf extract in J-Lat cells and monkey resting CD4+T cells. In total, $2 \times 10^{6}$ cells/well were treated with different concentrations of Pf (Pf 3d7) extract. Each treatment had three replications. Different dose-response patterns were found between J-Lat cells and primary monkey cells. After 48 hours of culture, for J-Lat cells, $5 \mu \mathrm{g} / \mathrm{ml}$ Pf extract could induce more histone acetylation, whereas $50 \mu \mathrm{g} / \mathrm{ml}$ Pf extract could sufficiently induce more histone acetylation in primary monkey cells. One-way ANOVA was used to compare the variables in this figure.

Additional file 4: Figure S4. The impact of Pf extract on HDAC activity. Pf extract did not influence the activity of HDAC in J-Lat cells and monkey PBMCs after 24 hours of stimulation. In total, $2 \times 10^{6}$ cells/well were treated with different concentrations of Pf (Pf 3d7) extract. Each treatment had three replications, and each assay had three replications. One-way ANOVA was used to compare the variables in this figure.

Additional file 5: Figure S5. The impact of LPS on the histone acetylation level of primary monkey cells. LPS did not influence the histone acetylation level of monkey lymphocytes or CD4+ T cells.

\section{Abbreviations}

HIV-1: Human immunodeficiency virus type-1; SIV: Simian immunodeficiency virus; ART: Antiretroviral therapy; iDNA: Integrated virus DNA; IUPM: Infectious units per million cells; PBMCs: Peripheral blood mononuclear cells; AIDS: Acquired immune deficiency syndrome; $T_{C M}$ : Central memory $T_{;} T_{E M}$ : Effector memory $T_{\text {; }}$

APCs: Antigen-presenting cells; IL-6: Interleukin-6; TNF-a: Tumor necrosis factor-alpha; PC: Plasmodium cynomolgi; IL-7: Interleukin-7; IL-2: Interleukin-2; IFN-ץ: Interferon-gamma; PBLs: Peripheral blood lymphocytes; VPA: Valproic acid; PHA: Phytohemagglutinin; MFI: Mean fluorescence intensity; Pf: Plasmodium falciparum; Pf dd2: Plasmodium falciparum strain dd2; Pf 3d7: Plasmodium falciparum strain 3d7; AcH3: Acetylated histone H3; LTRs: Long terminal repeats; Cq: Quantification cycle; HDAC: Histone deacetylase; CHIP: Chromatin immunoprecipitation; P. knowlesi: Plasmodium knowlesi; P. coatneyi: Plasmodium coatneyi; HZ: Hemozoin; FACS: Fluorescence-activated cell sorting; PMPA: 9-R-(2phosphonomethoxypropyl) adenine; FTC: Emtricitabine; RBCs: Red blood cells.

\section{Competing interests}

The authors declare that they have no competing interests.

\section{Authors' contributions}

$X Y Z$ performed the immunological assays and the in vitro experiments and data analysis. NW participated in the in vitro experiments and in drafting the manuscript. GL participated in performing the SIV RNA assays, PBMC isolation and PBMC-based SIV iDNA assays. LimQ participated in performing the immunological assays. WX participated in the in vitro Plasmodium culture. SZ helped with the experimental setup and provided reagents. XC and LiQ supervised all aspects of this study, including the study design, execution and interpretation and the manuscript preparation. All authors read and approved the final manuscript.

\section{Acknowledgments}

This work was supported by a grant from the Knowledge Innovation Program of the Chinese Academy of Sciences (Grant No. KSCX2-EW-J27), by the Science and Technology Planning Projects of Guangzhou (Grant No. 
2011 J2200002 and 201300000098), and by National Major Scientific and Technologic Special Project of China (Grant No. 2013ZX10001004) We thank Yi Zheng and Hongwen Pang at the Instrument Center of GIBH for assistance with instrument use. We are also grateful to Weimin Zhang, Jianfu Tao and Xiangjie Fen for help with rhesus macaque feeding and management. We give special thanks to Dr. Changzhong Chen at Brigham and Women's Hospital for help with the statistical analysis and to Dr. Zhiwei Chen at the AIDS Institute of the University of Hong Kong for kindly providing the J-Lat cell line. We also extend special thanks to the NIH for providing rhlL-2 and the J-Lat 10.6 cell line for this study.

Received: 22 August 2014 Accepted: 24 November 2014

Published online: 09 December 2014

\section{References}

1. WHO Joint United Nations Program on HIV/AIDS (UNAIDS): UNAIDS report on the global AIDS epidemic in 2013. http://www.unaids.org/en/media/ unaids/contentassets/documents/epidemiology/2013/gr2013/ UNAIDS_Global_Report_2013_en.pdf.

2. Chomont N, El-Far M, Ancuta P, Trautmann L, Procopio FA, Yassine-Diab B, Boucher G, Boulassel MR, Ghattas G, Brenchley JM, Schacker TW, Hill BJ, Douek DC, Routy JP, Haddad EK, Sekaly RP: HIV reservoir size and persistence are driven by $\mathrm{T}$ cell survival and homeostatic proliferation. Nat Med 2009, 15:893-900.

3. Combadiere B, Boissonnas A, Carcelain G, Lefranc E, Samri A, Bricaire F, Debre $P$, Autran B: Distinct time effects of vaccination on long-term proliferative and IFN-gamma-producing T cell memory to smallpox in humans. J Exp Med 2004, 199:1585-1593.

4. Shan L, Deng K, Shroff NS, Durand CM, Rabi SA, Yang HC, Zhang H, Margolick JB, Blankson JN, Siliciano RF: Stimulation of HIV-1-specific cytolytic T lymphocytes facilitates elimination of latent viral reservoir after virus reactivation. Immunity 2012, 36:491-501.

5. Stevenson MM, Riley EM: Innate immunity to malaria. Nat Rev Immunol 2004, 4:169-180

6. Chandele A, Mukerjee P, Das G, Ahmed R, Chauhan VS: Phenotypic and functional profiling of malaria-induced CD8 and CD4 T cells during blood-stage infection with Plasmodium yoelii. Immunology 2011, 132:273-286.

7. Li Q, Ruan Z, Zhang H, Peng N, Zhao S, Qin L, Chen X: Characterization of peripheral blood T lymphocyte subsets in Chinese rhesus macaques with repeated or long-term infection with Plasmodium cynomolgi. Parasitol Res 2012, 110:961-969.

8. Miyakoda M, Kimura D, Yuda M, Chinzei Y, Shibata Y, Honma K, Yui K: Malaria-specific and nonspecific activation of CD8+ T cells during blood stage of Plasmodium berghei infection. J Immunol 2008, 181:1420-1428.

9. Kublin JG, Patnaik P, Jere CS, Miller WC, Hoffman IF, Chimbiya N, Pendame $R$, Taylor TE, Molyneux ME: Effect of Plasmodium falciparum malaria on concentration of HIV-1-RNA in the blood of adults in rural Malawi: a prospective cohort study. Lancet 2005, 365:233-240

10. Kamya MR, Gasasira AF, Yeka A, Bakyaita N, Nsobya SL, Francis D, Rosenthal PJ, Dorsey G, Havlir D: Effect of HIV-1 infection on antimalarial treatment outcomes in Uganda: A population-based study. J Infect Dis 2006, 193:9-15.

11. Orlov M, Vaida F, Finney OC, Smith DM, Talley AK, Wang R, Kappe SH, Deng $Q$, Schooley RT, Duffy PE: P. falciparum enhances HIV replication in an experimental malaria challenge system. PLoS One 2012, 7:e39000.

12. Abu-Raddad LJ, Patnaik P, Kublin JG: Dual infection with HIV and malaria fuels the spread of both diseases in sub-Saharan Africa. Science 2006, 314:1603-1606.

13. Froebel K, Howard W, Schafer JR, Howie F, Whitworth J, Kaleebu P, Brown AL, Riley E: Activation by malaria antigens renders mononuclear cells susceptible to HIV infection and re-activates replication of endogenous HIV in cells from HIV-infected adults. Parasite Immunol 2004, 26:213-217.

14. Hoffman IF, Jere CS, Taylor TE, Munthali P, Dyer JR, Wirima JJ, Rogerson SJ, Kumwenda N, Eron JJ, Fiscus SA, Chakraborty H, Taha TE, Cohen MS, Molyneux ME: The effect of Plasmodium falciparum malaria on HIV-1 RNA blood plasma concentration. AIDS 1999, 13:487-494.

15. Chen S, Lai C, Wu X, Lu Y, Han D, Guo W, Fu L, Andrieu JM, Lu W: Variability of bio-clinical parameters in Chinese-origin Rhesus macaques infected with simian immunodeficiency virus: a nonhuman primate AIDS model. Plos One 2011, 6:e23177.
16. Lewis MG, DaFonseca S, Chomont N, Palamara AT, Tardugno M, Mai A, Collins M, Wagner WL, Yalley-Ogunro J, Greenhouse J, Chirullo B, Norelli S, Garaci $E$, Savarino A: Gold drug auranofin restricts the viral reservoir in the monkey AIDS model and induces containment of viral load following ART suspension. AIDS 2011, 25:1347-1356.

17. Pitcher CJ, Hagen SI, Walker JM, Lum R, Mitchell BL, Maino VC, Axthelm MK, Picker $L J$ : Development and homeostasis of $\mathrm{T}$ cell memory in rhesus macaque. J Immunol 2002, 168:29-43.

18. Chun TW, Engel D, Mizell SB, Ehler LA, Fauci AS: Induction of HIV-1 replication in latently infected CD4+ T cells using a combination of cytokines. J Exp Med 1998, 188:83-91.

19. Chun TW, Engel D, Mizell SB, Hallahan CW, Fischette M, Park S, Davey RT Jr, Dybul M, Kovacs JA, Metcalf JA, Mican JM, Berrey MM, Corey L, Lane HC, Fauci AS: Effect of interleukin-2 on the pool of latently infected, resting CD4+ T cells in HIV-1-infected patients receiving highly active anti-retroviral therapy. Nat Med 1999, 5:651-655.

20. Wang FX, Xu Y, Sullivan J, Souder E, Argyris EG, Acheampong EA, Fisher J, Sierra M, Thomson MM, Najera R, Frank I, Kulkosky J, Pomerantz RJ, Nunnari G: IL-7 is a potent and proviral strain-specific inducer of latent HIV-1 cellular reservoirs of infected individuals on virally suppressive HAART. J Clin Invest 2005, 115:128-137.

21. Hoshino S, Konishi M, Mori M, Shimura M, Nishitani C, Kuroki Y, Koyanagi Y Kano S, Itabe H, Ishizaka Y: HIV-1 Vpr induces TLR4/MyD88-mediated IL-6 production and reactivates viral production from latency. J Leukoc Biol 2010, 87:1133-1143.

22. Messele T, Abdulkadir M, Fontanet AL, Petros B, Hamann D, Koot M, Roos MT, Schellekens PT, Miedema F, Rinke de Wit TF: Reduced naive and increased activated CD4 and CD8 cells in healthy adult Ethiopians compared with their Dutch counterparts. Clin Exp Immunol 1999, 115:443-450.

23. Clerici MBS, Lukwiya M, Saresella M, Declich S, Trabattoni D, Pastori CPS, Fracasso C, Fabiani M, Ferrante P, Rizzardini G, Lopalco L: Immune activation in africa is environmentally-driven and is associated with upregulation of CCR5. Italian-Ugandan AIDS Project. AIDS 2000, 14:2083-2092.

24. Archin NM, Keedy KS, Espeseth A, Dang H, Hazuda DJ, Margolis DM: Expression of latent human immunodeficiency type 1 is induced by novel and selective histone deacetylase inhibitors. AIDS 2009, 23:1799-1806.

25. Archin NM, Liberty AL, Kashuba AD, Choudhary SK, Kuruc JD, Crooks AM, Parker DC, Anderson EM, Kearney MF, Strain MC, Richman DD, Hudgens MG, Bosch RJ, Coffin JM, Eron JJ, Hazuda DJ, Margolis DM: Administration of vorinostat disrupts HIV-1 latency in patients on antiretroviral therapy. Nature 2012, 487:482-485.

26. Williams SA, Chen LF, Kwon H, Fenard D, Bisgrove D, Verdin E, Greene WC: Prostratin antagonizes HIV latency by activating NF-kappa B. J Biol Chem 2004, 279:42008-42017.

27. Chan JK, Greene WC: Dynamic roles for NF-kappaB in HTLV-I and HIV-1 retroviral pathogenesis. Immunol Rev 2012, 246:286-310.

28. Haase AT: Targeting early infection to prevent HIV-1 mucosal transmission Nature 2010, 464:217-223.

29. Apetrei C, Pandrea I, Mellors JW: Nonhuman primate models for HIV cure research. Plos Pathog 2012, 8:e1002892.

30. Dinoso JB, Rabi SA, Blankson JN, Gama L, Mankowski JL, Siliciano RF, Zink MC, Clements JE: A simian immunodeficiency virus-infected macaque model to study viral reservoirs that persist during highly active antiretroviral therapy. J Virol 2009, 83:9247-9257.

31. Chen HY, Di Mascio M, Perelson AS, Ho DD, Zhang L: Determination of virus burst size in vivo using a single-cycle SIV in rhesus macaques. Proc Natl Acad Sci U S A 2007, 104:19079-19084.

32. Smith SM, Holland B, Russo C, Dailey PJ, Marx PA, Connor Rl: Retrospective analysis of viral load and SIV antibody responses in rhesus macaques infected with pathogenic SIV: predictive value for disease progression. AIDS Res Hum Retroviruses 1999, 15:1691-1701.

33. Zhou Y, Bao R, Haigwood NL, Persidsky Y, Ho WZ: SIV infection of rhesus macaques of Chinese origin: a suitable model for HIV infection in humans. Retrovirology 2013, 10:89.

34. Ling B, Veazey RS, Luckay A, Penedo C, Xu K, Lifson JD, Marx PA: SIV(mac) pathogenesis in rhesus macaques of Chinese and Indian origin compared with primary HIV infections in humans. AIDS 2002, 16:1489-1496.

35. Coatney GR, Collins WE, Warren M, Contacos PG: The Primate Malarias. Atlanta, GA: CDC, Division of Parasitic Diseases; 1971.

36. Brown AE, Webster HK, Teja-Isavadharm P, Keeratithakul D: Macrophage activation in falciparum malaria as measured by neopterin and interferon-gamma. Clin Exp Immunol 1990, 82:97-101. 
37. van der Sluis RM, van Montfort T, Pollakis G, Sanders RW, Speijer D, Berkhout B, Jeeninga RE: Dendritic cell-induced activation of latent HIV-1 provirus in actively proliferating primary T lymphocytes. Plos Pathog 2013, 9:e1003259.

38. Budd RC: Activation-induced cell death. Curr Opin Immunol 2001, 13:356-362

39. Alimonti JB, Ball TB, Fowke KR: Mechanisms of CD4+ T lymphocyte cell death in human immunodeficiency virus infection and AIDS. $J$ Gen Virol 2003, 84:1649-1661.

40. Toure-Bolde ASJ, Aribot GM, Trape J, Rogier C, Roussilhon C: P. falciparum induced apoptosis in human mononuclear cells. Infect Immunol 1996, 64:744-750.

41. Van Parijs $L$, Abbas AK: Homeostasis and self-tolerance in the immune system: turning lymphocytes off. Science 1998, 280:243-248.

42. Van Lint C, Emiliani S, Ott M, Verdin E: Transcriptional activation and chromatin remodeling of the HIV-1 promoter in response to histone acetylation. EMBO J 1996, 15:1112-1120.

43. Punsawad C, Krudsood S, Maneerat Y, Chaisri U, Tangpukdee N, Pongponratn E, Nantavisai K, Udomsangpetch R, Viriyavejakul P: Activation of nuclear factor kappa $B$ in peripheral blood mononuclear cells from malaria patients. Malar J 2012, 11:191.

44. Smith SM: Valproic acid and HIV-1 latency: beyond the sound bite. Retrovirology 2005, 2:56.

45. Aguilera O, Fernandez AF, Munoz A, Fraga MF: Epigenetics and environment: a complex relationship. J Appl Physiol 2010, 109:243-251.

46. Sinclair KD, Allegrucci C, Singh R, Gardner DS, Sebastian S, Bispham J, Thurston A, Huntley JF, Rees WD, Maloney CA, Lea RG, Craigon J, McEvoy TG, Young LE: DNA methylation, insulin resistance, and blood pressure in offspring determined by maternal periconceptional B vitamin and methionine status. Proc Natl Acad Sci U S A 2007, 104:19351-19356.

47. Ehrhardt H, Wachter F, Grunert M, Jeremias I: Cell cycle-arrested tumor cells exhibit increased sensitivity towards TRAIL-induced apoptosis. Cell Death Dis 2013, 4:e661.

48. Reddel RR, Murphy LC, Hall RE, Sutherland RL: Differential sensitivity of human breast cancer cell lines to the growth-inhibitory effects of tamoxifen. Cancer Res 1985, 45:1525-1531.

49. Chun TW, Justement JS, Murray D, Hallahan CW, Maenza J, Collier AC, Sheth PM, Kaul R, Ostrowski M, Moir S, Kovacs C, Fauci AS: Rebound of plasma viremia following cessation of antiretroviral therapy despite profoundly low levels of HIV reservoir: implications for eradication. AIDS 2010, 24:2803-2808.

50. Jiang B, Qin L, Du YH, Peng NZ, Chen L, Chen ZW, Chen XP: Transgenic Plasmodium that expresses HIV-1 Gag elicits immunity and protects mice against vaccinia virus-gag and malarial parasites. Vaccine 2010, 28:7915-7922.

51. Suryanarayana K, Wiltrout TA, Vasquez GM, Hirsch VM, Lifson JD: Plasma SIV RNA viral load determination by real-time quantification of product generation in reverse transcriptase-polymerase chain reaction. AIDS Res Hum Retroviruses 1998, 14:183-189.

52. Hofmann-Lehmann R, Swenerton RK, Liska V, Leutenegger CM, Lutz H, McClure HM, Ruprecht RM: Sensitive and robust one-tube real-time reverse transcriptase-polymerase chain reaction to quantify SIV RNA load: comparison of one- versus two-enzyme systems. AIDS Res Hum Retroviruses 2000, 16:1247-1257.

53. Yamamoto $N$, Tanaka C, Wu Y, Chang MO, Inagaki $Y$, Saito $Y$, Naito $T$, Ogasawara H, Sekigawa I, Hayashida Y: Analysis of human immunodeficiency virus type 1 integration by using a specific, sensitive and quantitative assay based on real-time polymerase chain reaction. Virus Genes 2006, 32:105-113.

54. Shen A, Zink MC, Mankowski JL, Chadwick K, Margolick JB, Carruth LM, Li M, Clements JE, Siliciano RF: Resting CD4+ T lymphocytes but not thymocytes provide a latent viral reservoir in a simian immunodeficiency virus-Macaca nemestrina model of human immunodeficiency virus type 1-infected patients on highly active antiretroviral therapy. J Virol 2003, 77:4938-4949.

55. Shen A, Yang HC, Zhou Y, Chase AJ, Boyer JD, Zhang H, Margolick JB, Zink MC, Clements JE, Siliciano RF: Novel pathway for induction of latent virus from resting CD4(+) T cells in the simian immunodeficiency virus/ macaque model of human immunodeficiency virus type 1 latency. J Virol 2007, 81:1660-1670.
56. Myers LE, McQuay $\amalg$, Hollinger FB: Dilution assay statistics. J Clin Microbiol 1994, 32:732-739.

57. Archin NM, Espeseth A, Parker D, Cheema M, Hazuda D, Margolis DM: Expression of latent HIV induced by the potent HDAC inhibitor suberoylanilide hydroxamic acid. AIDS Res Hum Retroviruses 2009, 25:207-212.

doi:10.1186/s12977-014-0112-x

Cite this article as: Zhan et al:: Plasmodium infection reduces the volume of the viral reservoir in SIV-infected rhesus macaques receiving antiretroviral therapy. Retrovirology 2014 11:112.

\section{Submit your next manuscript to BioMed Central and take full advantage of:}

- Convenient online submission

- Thorough peer review

- No space constraints or color figure charges

- Immediate publication on acceptance

- Inclusion in PubMed, CAS, Scopus and Google Scholar

- Research which is freely available for redistribution 